\title{
Binary Green Blends of Poly(lactic acid) with Poly(butylene adipate-co-butylene terephthalate) and Poly(butylene succinate-co-butylene adipate) and Their Nanocomposites
}

\author{
Serena Coiai $^{1}$ (D), Maria Laura Di Lorenzo ${ }^{2}\left(\mathbb{D}\right.$, Patrizia Cinelli ${ }^{3}$, Maria Cristina Righetti ${ }^{4, *(D)}$ \\ and Elisa Passaglia $1, *$ (D) \\ 1 CNR-ICCOM, National Research Council-Institute of Chemistry of OrganoMetallic Compounds, \\ 56124 Pisa, Italy; serena.coiai@pi.iccom.cnr.it \\ 2 CNR-IPCB, National Research Council-Institute of Polymers, Composites and Biomaterials, \\ 80078 Pozzuoli, Italy; marialaura.dilorenzo@ipcb.cnr.it \\ 3 Department of Civil and Industrial Engineering, University of Pisa, 56122 Pisa, Italy; patrizia.cinelli@unipi.it \\ 4 CNR-IPCF, National Research Council-Institute for Chemical and Physical Processes, 56124 Pisa, Italy \\ * Correspondence: cristina.righetti@pi.ipcf.cnr.it (M.C.R.); elisa.passaglia@pi.iccom.cnr.it (E.P.)
}

check for updates

Citation: Coiai, S.; Di Lorenzo, M.L.; Cinelli, P.; Righetti, M.C.; Passaglia, E. Binary Green Blends of Poly(lactic acid) with Poly(butylene adipate-cobutylene terephthalate) and Poly(butylene succinate-co-butylene adipate) and Their Nanocomposites. Polymers 2021, 13, 2489. https:// doi.org/10.3390/polym13152489

Academic Editor: Guoming Liu

Received: 29 June 2021

Accepted: 22 July 2021

Published: 28 July 2021

Publisher's Note: MDPI stays neutral with regard to jurisdictional claims in published maps and institutional affiliations.

Copyright: (c) 2021 by the authors. Licensee MDPI, Basel, Switzerland. This article is an open access article distributed under the terms and conditions of the Creative Commons Attribution (CC BY) license (https:// creativecommons.org/licenses/by/ $4.0 /)$.

\begin{abstract}
Poly(lactic acid) (PLA) is the most widely produced biobased, biodegradable and biocompatible polyester. Despite many of its properties are similar to those of common petroleum-based polymers, some drawbacks limit its utilization, especially high brittleness and low toughness. To overcome these problems and improve the ductility and the impact resistance, PLA is often blended with other biobased and biodegradable polymers. For this purpose, poly(butylene adipate-co-butylene terephthalate) (PBAT) and poly(butylene succinate-co-butylene adipate) (PBSA) are very advantageous copolymers, because their toughness and elongation at break are complementary to those of PLA. Similar to PLA, both these copolymers are biodegradable and can be produced from annual renewable resources. This literature review aims to collect results on the mechanical, thermal and morphological properties of PLA/PBAT and PLA/PBSA blends, as binary blends with and without addition of coupling agents. The effect of different compatibilizers on the PLA/PBAT and PLA/PBSA blends properties is here elucidated, to highlight how the PLA toughness and ductility can be improved and tuned by using appropriate additives. In addition, the incorporation of solid nanoparticles to the PLA/PBAT and PLA/PBSA blends is discussed in detail, to demonstrate how the nanofillers can act as morphology stabilizers, and so improve the properties of these PLA-based formulations, especially mechanical performance, thermal stability and gas/vapor barrier properties. Key points about the biodegradation of the blends and the nanocomposites are presented, together with current applications of these novel green materials.
\end{abstract}

Keywords: PLA; PBAT; PBSA; compatibilization; biodegradation; reactive blending; nanocomposites

\section{Introduction}

Biodegradable and/or biobased polyesters are "green polymers" with huge potential to replace traditional fossil-based polymer materials, and are needed to limit exploitation of fossil resources and global warming, as well as to reduce environmental pollution [1,2]. A wide variety of green polyesters are currently available on the market, thanks to their wide range of favorable properties that can be tailored by chemical architecture and processing. Additional fine tuning can be achieved by blending, which is a common and cost-efficient way to manipulate the physical properties of polymer materials.

Poly(lactic acid) (PLA) is the most widely produced biodegradable and biobased polyester [3,4], and is the most promising candidate for substitution of oil-based polymers in several commodities and engineering applications. At room temperature, the mechanical properties of PLA are comparable to those of the petroleum-based polystyrene [5], whereas 
the thermal properties as a whole differ from those of other commodity plastics: the melting temperature of PLA is similar to that of polypropylene, but its glass transition temperature is markedly higher, although lower than that of poly(ethylene terephthalate) and polystyrene. Being biodegradable and produced from renewable resources, and also having non-toxic features, PLA is the ideal polymeric platform for the design and manufacture of packaging for food, especially for that of large consumption and with a short shelf-life [6-8]. Moreover, owing to its biocompatibility, it attracts interest for a range of biomedical applications such as scaffolding and tissue engineering [3,4].

Despite its known advantageous characteristics, PLA suffers from some drawbacks such as brittleness, low toughness, low heat distortion temperature, narrow processing temperature window, low melt strength and low crystallization rate. To overcome and improve some of these non-beneficial characteristics, with particular reference to low processability, ductility and impact resistance, PLA can be blended with other equally biodegradable polymers which have high ductility, high melt strength and thus better processability [7-9]. Among the various biodegradable polymers, poly(butylene adipate-cobutylene terephthalate) (PBAT) and poly(butylene succinate-co-butylene adipate) (PBSA) are the most used and promising candidates, because the physical properties of some PBAT and PBSA copolymers, like high toughness and elongation at break [7] are complementary to those of PLA.

Both these copolymers contain two different comonomers randomly sequenced: in PBAT one of the comonomers is butylene terephthalate (BT), which is derived from terephthalic acid and 1,4-butanediol, and the other is the butylene adipate (BA), which is ductile and produced from adipic acid and 1,4-butanediol; similarly, in PBSA one of the comonomers is BA, whereas the other is butylene succinate (BS), which is achieved by condensation of succinic acid and 1,4-butanediol. Formally, PLA also needs to be considered a copolymer, being produced from lactic acid, which has an enantiomeric carbon atom, and the PLA grades available on the market contain various amounts of L- and D-isomers. The main thermal and mechanical properties of PLA, PBAT and PBSA are reported in Table 1.

Table 1. Thermal and mechanical properties (glass transition temperature, $T_{\mathrm{g}}$; melting temperature, $T_{\mathrm{m}}$; tensile strength, TS; elongation at break, $\varepsilon$; elastic modulus, E) of PLA, PBAT, and PBSA.

\begin{tabular}{|c|c|c|c|c|c|}
\hline Polymer & $T_{\mathrm{g}}\left({ }^{\circ} \mathrm{C}\right)$ & $T_{\mathrm{m}}\left({ }^{\circ} \mathrm{C}\right)$ & TS (MPa) & $\varepsilon(\%)$ & $E(\mathrm{MPa})$ \\
\hline PLA & 55-60 [10] & $150-180$ [10] & $15-60[6]$ & 3-10 [6] & $3500-4000$ [6] \\
\hline PBAT & $-60--10[11]$ & $\begin{array}{c}50-30^{1} \\
70-190^{2}[11]\end{array}$ & $10-20$ [12] & $\begin{array}{c}600-100^{1} \\
10-100^{2}[12]\end{array}$ & $\begin{array}{c}40-100^{1} \\
400-100^{2}[12]\end{array}$ \\
\hline PBSA & $-60--35[13]$ & $\begin{array}{c}20-50^{3} \\
50-110^{4}[13]\end{array}$ & $\begin{array}{c}12-10^{3} \\
20-10^{4}[14]\end{array}$ & $\begin{array}{c}380-330^{3} \\
430-330^{4}[14]\end{array}$ & $300^{1,5}$ \\
\hline
\end{tabular}

${ }^{1}$ BA-rich copolymers (PBAT); ${ }^{2}$ BT-rich copolymers (PBAT); ${ }^{3}$ BA-rich copolymers (PBSA); ${ }^{4}$ BS-rich copolymers (PBSA); ${ }^{5}$ From leaflet of commercial Bionolle ${ }^{\mathrm{TM}} 3000$ (approximately BA: $20 \mathrm{~mol} \%$, BS: $80 \mathrm{~mol} \%$ ).

A number of reviews detailing improvement of PLA properties by blending have been recently published [7-9,15-29], but none of them deals specifically with blends of PLA with PBSA or PBAT. Having these blends high potential as novel green materials, we present in this contribution an overview of main literature results on PLA/PBSA and PLA/PBAT blends. Literature data detailed here also include formulations containing nanofillers, which impart improved properties to the blends.

The review starts with a short summary of the main features of PLA, PBSA and PBAT, followed by in-depth analysis of preparation and characterization of PLA/PBAT and PLA/PBSA blends and their nanocomposites. Biodegradation of PLA/PBAT and PLA/PBSA is also detailed and discussed. The review ends with examples of industrial applications of these green blends and nanocomposites. 


\section{Synthesis, Structure and Properties of PLA, PBAT and PBSA}

\subsection{Poly(lactic acid)}

PLA is produced by ring-opening polymerization of lactide, the cyclic dimer of 2hydroxypropanoic acid, $\mathrm{CH}_{3}-\mathrm{CH}(\mathrm{OH})-\mathrm{COOH}$, better known as lactic acid (LA) [30-32]. LA is a naturally occurring organic acid with a chiral carbon atom, which leads to two enantiomers, named L-lactic acid (L-LA) and D-lactic acid (D-LA). Production of LA from petrochemical resources leads to a racemic L-LA/D-LA mixture, i.e., to a low quality product [33]. LA can also be produced by microbial fermentation, which not only allows to attain L-LA or D-LA with high optical purity [31], but also implies the use of renewable carbohydrate biomass as feedstock, and low energy consumption due to low temperature processing. In fact, industrial production of LA uses microbial fermentation technology.

The bacteria typically used in industrial fermentation mainly produce L-isomer [31]. Therefore, most commercial PLA grades are based on L-LA, and contain only 1-4\% D-units. For this reason, the polymer is often named poly(L-lactic acid) even if it contains small amounts of D-LA. The L-LA and D-LA units are randomly sequenced in PLA chains, with the result that PLA is a random copolymer, and its properties are largely affected by the co-unit ratio $[32,33]$.

PLA is a polymorphic polyester [34]. Quiescent crystallization leads to growth of only two crystal modifications: $\alpha$-crystals that develop above $120^{\circ} \mathrm{C}$, and $\alpha^{\prime}$-crystals that grow at lower temperatures. Material properties, including thermal properties, mechanical performance and gas barrier properties are largely affected by crystal modification $[35,36]$.

The glass transition temperature $\left(T_{\mathrm{g}}\right)$ of highly stereoregular PLA is around $60{ }^{\circ} \mathrm{C}$, with lower values observed in grades with poorer stereoregularity [10]. Also the melting temperature is affected by L-/D-isomer ratio. It is around $150-180{ }^{\circ} \mathrm{C}$, decreasing with the D-content [10], with the exact value also depending on crystallization temperature and thermal history [10], as typical for semicrystalline polymers. PLA is a slowly crystallizing polymer. The crystallization ability of PLA depends on the D-unit amount, because both crystallization rate and crystallinity degree decrease with increasing the D-unit percentage [37]. PLA copolymers containing more than $10-15 \%$ of randomly distributed D-units are totally amorphous [10]. The smallest crystallization half-time is of a few minutes at about $110{ }^{\circ} \mathrm{C}$ for $0 \%$ D-isomer content, but it increases more than one order of magnitude if the crystallization temperature is increased or reduced by about $20 \mathrm{~K}$. Such crystallization rate values are often too slow for industrial processing routes.

As regards biodegradation, it is known that complete degradation of PLA in soil is quite slow (about a year), whereas it is faster in industrial compost conditions, which imply higher temperature (about 100 days) [38].

Despite several favorable properties, like high elastic modulus, marked scratch resistance, high transparency, biodegradability, industrial compostability, good printability and heat sealability [39], PLA presents a few drawbacks that limit a wider industrial exploitation, especially the high brittleness, the low impact strength and the brittle fracture behavior at very low strain [40].

\subsection{Poly(butylene adipate-co-terephthalate)}

PBAT is a linear aliphatic-aromatic random copolyester obtained by polycondensation of 1,4-butanediol, adipic acid and terephthalic acid, which can be produced from either fossil or annually renewable resources [41,42]. Succinic acid can be attained from fermentation of carbohydrates [43-46], and 1,4-butanediol can be produced via hydrogenation and reduction of succinic acid [47]. Biobased terephthalic acid can be synthesized from isobutene [48] or limonene [49]. Adipic acid can also be produced through environmentally friendly paths, by biomass fermentation or using glucose [50], lignin [51] or fatty acids [52], although the costs are still high [53].

PBAT is a random copolymer, such that its properties, strongly depending on composition, can be tuned by proper balance of BA and BT co-units [54]. The glass transition temperature ranges from -60 to $-10^{\circ} \mathrm{C}$, and increases with BT amount [11]. The copoly- 
mers are semicrystalline, with crystallization kinetics and melting largely affected by composition [11,13,55]. When BT content is below $20 \mathrm{~mol} \%$, the BA units crystallize into monoclinic poly(butylene terephthalate) (PBA) crystals, whereas PBT content higher than $30 \%$ leads to growth of orthorhombic poly(butylene terephthalate) (PBT) crystals. In copolymers containing $20-30 \mathrm{~mol} \%$ of BT units, both PBA and PBT crystals can be detected $[11,13,55]$. Co-crystallization of the co-units was also suggested, where BA segments fit into the crystal structure of PBT by adopting a TTGTG dihedral angle sequence [55-57]. The fastest crystallization of the BA-rich copolymers occurs between -20 and $0{ }^{\circ} \mathrm{C}$, depending on the BA content, and the rate ranges from about 3 to $10 \mathrm{~min}^{-1}$ with increasing BA content. At room temperature, the crystallization rate of the BA-rich copolymers is comprised approximately between 0.05 and $1 \mathrm{~min}^{-1}$. Crystallization of the BT co-units occurs at temperatures increasing with the $\mathrm{BT}$ amount. The highest crystallization rate occurs from 20 to $120^{\circ} \mathrm{C}$, and increases from 0.5 to $10 \mathrm{~min}^{-1}$ [11]. Crystallinity increases in the BA- and BT-rich copolymers with increasing the BA and BT content respectively, from about $10 \%$ to $50 \%$ [11].

Biodegradation of PBAT depends on chemical structure [58,59]. PBAT has been reported to be degraded in a few weeks in soil [13]. However, biodegradation rate decreases significantly with an increasing fraction of aromatic units [60,61]. All co-units can be degraded by microorganisms: ${ }^{13} \mathrm{C}$-labeling of the co-units, needed to distinguish polymer-derived $\mathrm{CO}_{2}$ from $\mathrm{CO}_{2}$ formed by soil organic matter mineralization, allowed to demonstrate that soil microorganisms use carbon from all the monomer units of PBAT to gain energy and form biomass [62]. However, the maximum content of terephthalic acid for PBAT materials to remain compostable is around $60 \mathrm{~mol} \%[60,61]$.

Mechanical properties of PBAT are also affected by composition. Young's modulus increases with content of terephthalate units, while elongation at break decreases [13]. Molar mass has deep influence on mechanical properties, as tensile strength increases, and elongation at break decreases with the increase of molar mass [42].

The widely utilized commercial Ecoflex ${ }^{\circledR}$, produced by BASF, is a PBAT copolymer with a BT amount of approximately $40 \mathrm{~mol} \%$, glass transition temperature around $-32{ }^{\circ} \mathrm{C}$ and melting temperature close to $110^{\circ} \mathrm{C}$. All the PLA/PBAT blends discussed below were prepared by using commercial copolymers with this comonomers composition.

\subsection{Poly(butylene succinate-co-adipate)}

PBSA can be a fully biobased copolyester, generally produced by polycondensation reaction of 1,4-butanediol in the presence of succinic acid and adipic acid [63-65]. The co-mononers of PBSA have similar chemical structure, as they only differ in the number of methylene units of their dicarboxylate unit $\left(2 \mathrm{CH}_{2}\right.$ in succinic acid and $4 \mathrm{CH}_{2}$ in adipic acid), and the corresponding homopolymers, i.e., poly(butylene succinate) (PBS) and poly(butylene adipate) (PBA) have been reported as miscible in the amorphous state [66].

PBSA copolymers are semicrystalline and display crystal isodimorphism, as the different comonomer units can co-crystallize in the same crystal lattice with some distortion of the unit cell $[12,67]$. Crystallization and melting temperatures, crystal fraction and transition enthalpies display a pseudoeutectic behavior as a function of composition, located at $50-60 \mathrm{~mol} \%$ of BA units $[12,68]$. For BA-rich compositions, the inclusion of butylene succinate units in the copolymer selectively promotes formation of the orthorhombic $\beta$-polymorph, instead of the commonly observed monoclinic $\alpha$-structure. The unit cell parameters are composition-dependent and switch from PBS-like unit cells to $\beta$-PBA-like unit cells around the pseudoeutectic point. However, at these compositions, depending on the specific thermal history, especially the cooling rate from the melt, the copolymer can display single- or double-crystalline character [12]. Crystallization of the BA units occurs between $5{ }^{\circ} \mathrm{C}$ and $30^{\circ} \mathrm{C}$, whereas crystallization of the BS units takes place between $15^{\circ} \mathrm{C}$ and $80^{\circ} \mathrm{C}$, at temperatures increasing with the BA and BS content, respectively. Crystallization rates are high also at high cooling rate in the BA- and BS-rich copolymers [12]. 
Crystallinity degree varies from 30 to $50 \%$ in the BA-rich copolymers and from 30 to $60 \%$ in the BS-rich copolymers [14].

The glass transition temperature varies with copolymer composition, ranging from $-60{ }^{\circ} \mathrm{C}\left(\mathrm{T}_{\mathrm{g}}\right.$ of $\left.\mathrm{PBA}\right)$ to $-35^{\circ} \mathrm{C}$, always displaying single glass transition temperature, as expected for random copolymers whose co-units form a miscible amorphous phase [12,14]. Similarly, mechanical properties and biodegradability vary with co-unit content, which in turn determines crystallinity of the material. Compared to PBS, tensile strength decreases with increasing adipate units, passing through a minimum at copolyester composition close to equimolarity, and then increases with higher content. Like the corresponding homopolymers, all copolymers are highly ductile, with small variations in maximum achievable elongation observed for adipate unit content of $20-40 \mathrm{~mol} \%$ [14].

PBSA copolymers are biodegradable in the whole composition range by several enzymes, like Candida cylindracea lipase, Rhizopus delemar lipase, and Pseudomonas fluorescens cholesterol esterase, with the maximum degradation rate reported for grades having the lowest crystal fraction, which corresponds to equimolar content of BA and BS co-units. This suggests that for PBSA copolymers, crystallinity is the major factor determining the enzymatic degradation rate [14,69].

PBSA commercial grades contain about $20 \mathrm{~mol} \%$ of BA, and have a glass transition temperature around $-45{ }^{\circ} \mathrm{C}$ and melting temperature close to $95^{\circ} \mathrm{C}$. The PLA/PBSA blends discussed below deal with PBSA commercial grades with the above composition.

\section{PLA/PBAT and PLA/PBSA Blends: Preparation and Characterization}

Due to the complementary properties of PBAT and PBSA with those of PLA, it has been widely proved as detailed below, that the processability and toughness of PLA can be significantly improved if it is mixed with PBAT or PBSA.

It has been demonstrated that the pairs PLA and PBAT, as well as PLA and PBSA, are generally not miscible [70-89]. The properties of binary blends of immiscible polymers depend on morphology, which depends on the concentration ratio of the two polymers, processing methods, and especially the shear viscosities of the two polymers at the processing temperatures. Generally, the major component constitutes the continuous phase while the minor one the dispersed phase. This latter is in the form of spherical or elongated particles (as fibrils), more or less adhered to the matrix according to the equilibrium between break-up and coalescence phenomena, which are strongly influenced by the rheological features of polymers and experimental conditions. Co-continuous morphology is generally observed at intermediate compositions.

Studies on the correlation between the morphology of PLA/PBAT and PLA/PBSA blends and their mechanical properties can be found in the literature $[71-74,76,77,79,80,84,87,88]$. The main aim of these studies was the optimization of the blend morphology to obtain tough PLA-based materials. However, this simple blending approach may not be efficient for industrial applications. Thus, coupling agents and other chemicals were used to increase the compatibility between the two components and suitably modulate the morphology and thermomechanical properties of the blends (reactive blending).

\subsection{PLA/PBAT and PLA/PBSA Mixtures by Blending}

In the latest 10 years many works have been published on PLA/PBAT and PLA/PBSA blends with the soft polymer used as dispersed phase to toughen PLA. Although some authors have shown that PBAT is miscible with PLA for concentrations equal to or lower than $2.5 \mathrm{wt} \%$ [86,89], for greater ratios, PBAT is immiscible with PLA, as well as PBSA.

The ability to make PLA-based materials tough is measured by the increase in the elongation at break while maintaining good values of strength and stiffness, in agreement with the typical values of rubber toughened polymer blends. To this purpose, the dispersed phase (PBAT or PBSA) has to be characterized by small and spherically-shaped particles, having less than $1 \mu \mathrm{m}$ in size and being uniformly embedded in the PLA matrix. 
Nofar et al. [71,72,76,77] extensively studied the blending of amorphous or semicrystalline PLA (A-PLA and SC-PLA, respectively) with PBAT and PBSA at $75 / 25 \mathrm{wt} \%$ ratio, by using PLA with different molar mass (LPLA and HPLA, low and high molar mass, respectively) and by changing the blending procedure (injection molding (IM), melt mechanical mixing (MM), or twin screws extrusion (TS)). All the results concerning the mechanical behavior were explained by considering the morphology of the blends. Blends with similar morphology, i.e., where the dispersed soft phase presents spherical domains with various diameter up to $1 \mu \mathrm{m}$, showed also similar tensile behavior. For example, in both LPLA/PBAT (MM) and LPLA/PBSA (MM), the strain at break increased to about $150 \%$, which is a good result considering that the strain at break of LPLA is about $5 \%$. Additionally, HPLA/PBAT (TS) revealed much higher ductility (265\%) compared to HPLA/PBAT (MM) owing to small, dispersed droplet size $(0.5 \mu \mathrm{m})$. However, when SC-PLA and TS were used as matrix and mixing method, respectively, the blend with PBAT was more uniform with much finer dispersed PBAT droplets and ductility improved up to $205 \%$; while by IM only the SC-PLA-based blend was sufficiently ductile. In addition, crystallization of PBAT occurring at about $60^{\circ} \mathrm{C}$, before the A-PLA vitrification, provided a non-uniform and coarse dispersed phase with detriment of mechanical features. A similar behavior was observed for A-PLA/PBSA where the vitrification of PLA hindered the crystallization of PBSA, thus resulting in a worse morphology with non-effective inter-macromolecular interactions or bonding at the interface.

Crystallization rate of PLA is generally increased by PBAT, although with small effect on crystallinity. The maximum of the crystallization rate shifts to lower temperatures with increasing the PBAT content [90]. However, processing conditions generally do not allow PLA crystallization, due to its low crystallization rate. Conversely, crystallization of PBAT and PBSA takes place upon cooling, depending on the cooling rate [71,84]. Melting of PBAT is located in the cold crystallization range of PLA (about $110^{\circ} \mathrm{C}$ ), so that it is impossible to determine the PBAT crystallinity degree by differential scanning calorimetry upon heating. But, if quantified upon cooling, an estimation of the PBAT crystallinity in PLA/PBAT blends can be obtained. It is generally about $15 \%$. Conversely, melting of PBSA does not overlap PLA crystallization, because it takes place at lower temperatures (about $90{ }^{\circ} \mathrm{C}$ ), thus PBSA crystallinity valuation in PLA/PBSA blends can be attained from heating scans (approximately 30\%) [71,84].

The immiscibility of the blends was assessed not only by morphological evidence, but also considering the typical DSC results. PLA/PBAT and PLA/PBSA blends studied in a wide range of compositions as discussed in Refs. [70,80,82,88], exhibit two $T_{\mathrm{g}}$ regions, clearly indicating that the polymers are not miscible and that a structure with separate components develops. However, a small $T_{\mathrm{g}}$ decrease in the PLA-rich blends was detected, which was connected to a limited partial miscibility of PBAT with PLA. This effect strongly depends on the PLA molar mass, thus suggesting the partial miscibility has to be ascribed to entropic contribution [79].

The toughening of PLA with a varying content of PBAT by using TS as processing method was investigated and related to the dimension of the dispersed phase (Figure 1).

As reported by Gigante et al. [74], it could be immediately noticed from stress-strain curves (Figure 1) that the tensile feature of PLA changed remarkably with the amount of PBAT. The increase in elongation at break for blends with 20 and $25 \mathrm{wt} \%$ of PBAT reached around 300 and 350\%, respectively. At the same time, the modulus did not collapse and overall Charpy impact strength values were higher than that of pristine PLA. This result confirmed that the increase in ductility and tenacity did not negatively affect the polymer stiffness with a general trend perfectly fitting the behavior of rubber toughened polymer blends. It is well-known that the ductile phase finely dispersed in a plastic/brittle matrix hinders the development of fractures by absorbing the energy of the break. Such a characteristic was related to the low dimensions of PBAT particles whose diameter was in the range of hundreds of nanometers, below the micron size for all investigated 
compositions (inset in Figure 1). By increasing the content of PBAT, the morphology was featured by spherical droplets increasingly bigger and not homogeneous.

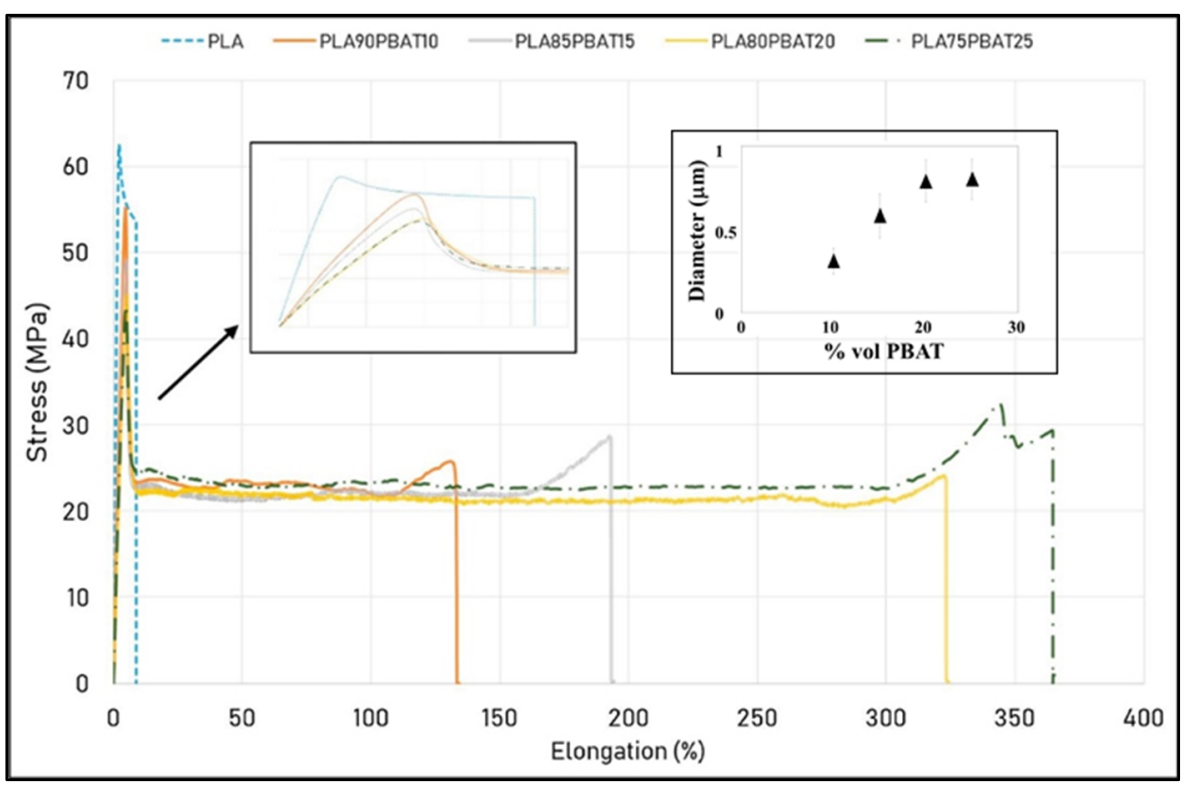

Figure 1. Stress-strain curves of PLA/PBAT blends and in the inset particle dimension analysis. Reprinted (adapted) with permission from Ref. [74]. Copyright 2019 Elsevier.

Li et al. [86] earlier observed a clear morphology change by increasing the content of polymeric soft phase in PLA blends. They observed an elongation of the droplet particles until reaching a co-continuous phase (with PBAT around 40-60 wt \%) and then again, a phase separation with PLA as the dispersed phase (with PBAT greater than $70 \mathrm{wt} \%$ ). More recently this behavior was better investigated by Deng et al. [73]. They prepared PLA/PBAT blends with different ratios (90/10, 80/20, 60/40, 50/50, 40/60, 80/20) and used a simple empirical equation (Equation (1)) to predict the morphological features, and composition range in which a dual co-continuous phase develops, which was correlated with the rheological, thermal, and overall mechanical performances. In the region of co-continuous phase significant improvement in ductility would be expected.

$$
\frac{\varphi_{1}}{\varphi_{2}}=\frac{\eta_{1}}{\eta_{2}}
$$

Equation (1) states that for immiscible polymer blends, a dual phase co-continuity develops when the ratio of volume fractions of components 1 and $2\left(\varphi_{1}\right.$ and $\left.\varphi_{2}\right)$ is equal to the ratio of their respective shear viscosities $\left(\eta_{1}\right.$ and $\left.\eta_{2}\right)$ at the processing temperature. In addition, if the viscosity ratio $\left(\eta_{1} / \eta_{2}\right)$ is higher than the ratio of volume fractions, component 2 is the continuous phase, with component 1 forming the dispersed phase. Results of melt rheology allow calculating the viscosity ratio at the processing temperature, and thus the volume fractions at which a co-continuous phase structure begins to form. The critical value of $\varphi_{P B A T}$ was calculated to be about $18 \mathrm{wt} \%$.

The thermal, morphological and mechanical features of the blends were studied and it was shown that the elongation at break (Figure 2a) increased significantly in the composition range between 10 and $20 \mathrm{wt} \%$ (see also the inset of Figure 2a). This improvement was regarded as evidence of co-continuous phase formation with a good agreement with predicted composition. The strain was constant at about 300\% till PBAT reached $40 \mathrm{wt} \%$. Indeed, a sharp falling between 40 and $50 \mathrm{wt} \%$ with ductility improvement for PBAT content greater than $60 \mathrm{wt} \%$ was observed. The drop between 40 and $50 \mathrm{wt} \%$ of PBAT corresponds to a further morphology change, passing from co-continuous to dispersed morphology with PLA large domains in the PBAT matrix (as proved by SEM analysis). 
When the content of PBAT increased above $60 \mathrm{wt} \%$, a very ductile behavior was observed reflecting the decrease of PLA droplets' dimension. Both Young's modulus (Figure $2 b$ ) and tensile strength showed trends well-fitting the Parallel's model [73] for PBAT content up to $40 \mathrm{wt} \%$, thus confirming that PLA is acting as a continuous phase. Above PBAT content of $40 \mathrm{wt} \%$, a dramatic decrease in Young's modulus with a trend better fitted by Series's model was observed thus suggesting variations in morphology. Accordingly, the morphology variation was schematized as reported in Figure 2c. Results showed not only a better ductility behavior, due to the formation of co-continuous phases, but also that this effect can be tuned and optimized by changing the viscosity ratio and the processing parameters. As regards the phase composition, PLA crystallinity was found to slightly increase with the PBAT amount, from about $0 \%$ in pure PLA, to approximately $20 \%$ for the PBAT/PLA 80/20 blend, proving that PBAT acts as nucleating agent for PLA [73].
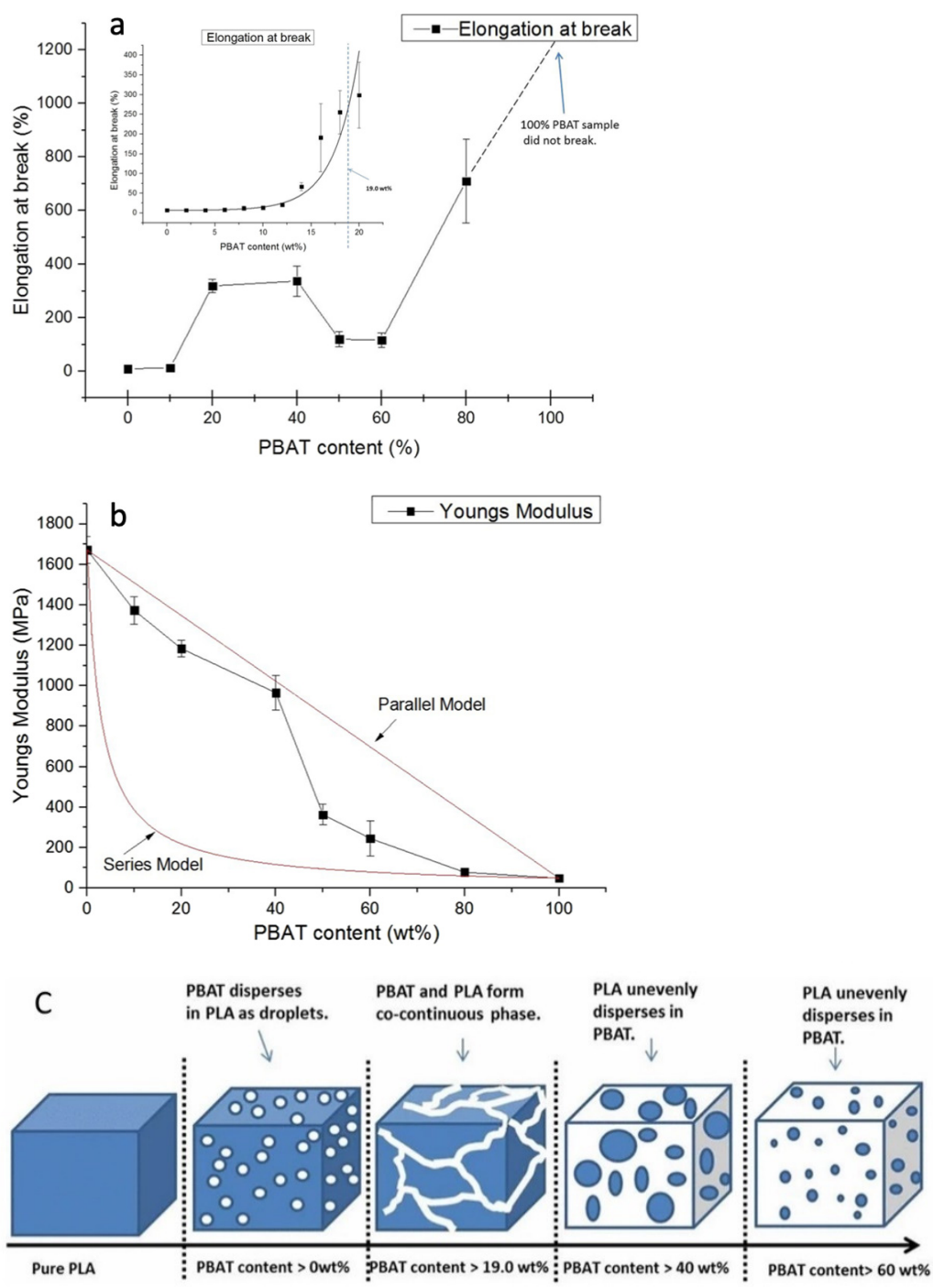

Figure 2. (a) Elongation at break, (b) Young's modulus and (c) schematic representation of phase structure of PLA/PBAT blends as a function of composition. Reprinted (adapted) from Ref. [73].

Similar results were obtained by mixing PLA with PBSA. For example, Ojijo et al. [84] studied the mechanical properties and morphology of blends with different composition: PLA/PBSA 90/10, 70/30, 60/40, 50/50, 40/60, 30/70, 10/90. In this case the co-continuous morphology is formed at a rather high percentage of PBSA (60 $\mathrm{wt} \%)$. For higher PBSA amount, phase inversion is observed, with dispersed spherical particles of PLA in the PBSA matrix. At the processing temperature $\left(185^{\circ} \mathrm{C}\right)$, the viscosity of PBSA was much lower than 
that of PLA, which explains why PBSA failed to deform PLA thus generating larger PLA droplets than PBSA dispersed in the opposite but corresponding composition (Figure 3). Better results in terms of elongation and tensile modulus were obtained for the 70/30 composition; at this composition, the surface area of PBSA domains, which was estimated from SEM images, was maximized and thus increased the interfacial entanglement of polymer components chains. Investigation of the thermal properties demonstrated that an increase in the crystallization rate occurred in the PLA-rich blend by increasing the PBSA content, which attests the nucleation action exerted by PBSA in the molten state. Conversely, for the PBSA-rich blends, an increase in PBSA produced a PLA crystallization retardation. PLA crystallinity was found to increase from zero for plain PLA up to about $10 \%$ for PLA/PBSA $60 / 40$ blend. PBSA was found to exhibit fractionated crystallization, which is due to different heterogeneities that, depending on the droplets size, induce nucleation at different undercooling [84].

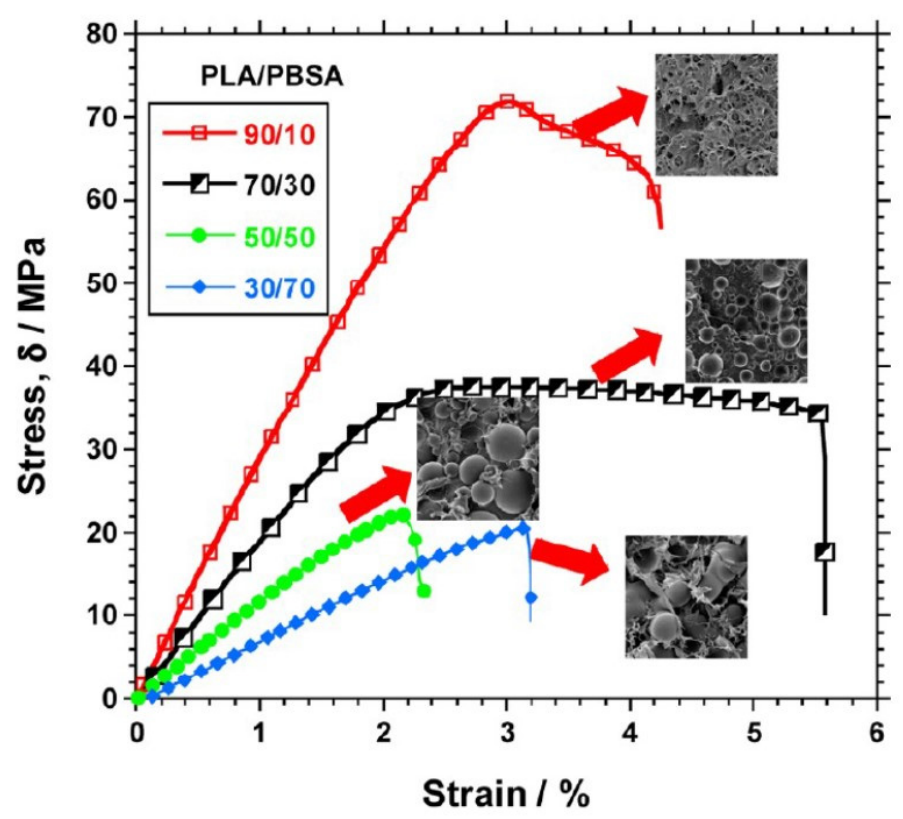

Figure 3. Stress strain curves and SEM micrographs of selected PLA/PBSA blends at different composition. Reprinted with permission from Ref. [84] Copyright 2012 American Chemical Society.

To improve the mechanical features of PLA-based blends with PBAT and PBSA, some annealing procedures to induce crystallization were used [80,82,84]; generally, the annealing process worsened the phase separation causing lowering of impact and tensile strength, but some improvement in heat distortion temperature were collected owing to increased crystallinity of PLA [82].

\subsection{PLA/PBAT and PLA/PBSA Mixtures by Reactive Blending}

The works previously analyzed have highlighted that it is possible to improve the toughness and ductility of PLA through mixing with PBAT and PBSA. However, the intrinsic immiscibility between the polymers prevents developing blends with morphologies and then ultimate properties optimized for final applications. Some debonding phenomena are easily detectable even when co-continuous and/or dispersed phase (soft) has dimensions below the micron [73]. This effect results in improved elongation at break, but causes a marked reduction in the PLA tensile strength.

The compatibility between components can be improved by modifying the interface, thus controlling blends properties. The modification can be performed with pre-made or in situ generated copolymers. The addition of specially tailored copolymers, mainly polyethylene glycol-polylactic acid (PEG-PLA) di- or tri-block copolymers to PLA/PBSA and PLA/PBAT blends resulted in appreciable toughening of PLA [91,92], but the mul- 
tistep and expensive preparation procedure of these block copolymers is not technologically favorable. Many authors utilized the reactive blending process, which consists of adding chemicals with a high or low molecular weight capable of forming covalent inter-macromolecular bonds.

Two main approaches, based on the use of typical reagents of the chain extender family, were investigated: (1) the reactive blending with chemicals able to directly generate covalent bonds between PLA and PBAT or PLA and PBSA; (2) the reactive blending with chemicals able to react with the end groups of the polymers that are part to the extended chains.

Among the first class of reagents, the use of peroxides grants the possibility to generate inter-macromolecular covalent bonds between PLA e PBAT, producing a PLA-PBAT copolymer, which acts as a compatibilizer at the interface [93-96]. Coltelli et al., studied the reactivity of PLA, PBAT and PLA/PBAT 75/25 towards 2,5-dimethy-2,5-di(tertbutylperoxy) hexane [93] by evidencing the nonselective strategy of this approach. The reaction mechanism is very complex and involves the coupling between all macroradicals, causing the formation of branched and partially crosslinked PLA and PBAT. The latter species were in different percentages, due to the different reactivity of each polymer towards radicals. PBAT was found to have a greater ability to form radical reactive species than PLA, due to the higher content of $\mathrm{H}$-atoms extractable from its backbone. In any case, some experimental data (torque evolution) showed that, for 0.2 and $0.4 \mathrm{wt} \%$ of peroxide, there was a consistent amount of PLA-PBAT copolymer formation. At the concentration of about $0.2 \mathrm{wt} \%$ of peroxide the dispersed phase diameter reached a minimum, thus maximizing the inter-macromolecular reactions (and also the formation of PLA-PBAT copolymer) as well as the interface interaction. In fact, for this composition the elongation at break was improved up to a maximum value. The presence of peroxide changed the thermal behavior of the blends, by favoring the PLA crystallization both upon cooling and heating [93].

Ma et al. [94] and Signori et al. [95] studied the structural and thermomechanical behavior of PLA/PBAT mixtures 80/20 and Ecovio ${ }^{\circledR}$, a commercial compound of PLA and PBAT having about $80 / 20$ composition, by increasing the content of dicumyl peroxide (DCP). The domain size of dispersed phase (PBAT) decreased by increasing the content of DCP from 0.1 to $0.5 \mathrm{wt} \%$ and the interface became less distinguishable, suggesting the occurrence of stronger interfacial interaction. In these conditions, a high elongation at break up to $300 \%$ was obtained, but PLA/PBAT blend with content of DCP less than $0.1 \mathrm{wt} \%$ showed brittle impact fracture. However, by increasing the content of DCP, a tougher behavior was observed. Similarly, the storage modulus of Ecovio ${ }^{\circledR}$ increased by increasing the content of DCP. This trend, suggesting an increased toughness of the blend, agreed with the occurrence of progressively increased crosslinking mainly involving the dispersed PBAT phase (as shown by the solvent extractions results). In addition, dynamic mechanical analysis (DMA) measurements showed higher dynamic glass transition with DCP content according to the progressively reduced chains mobility (Figure 4). The amorphous/crystalline ratio of the PBAT regions was found to be independent of the DCP content, whereas the PLA crystallinity increased when the blends underwent thermal cycles. The PLA cold crystallization shifted to lower temperature with increasing DCP amount, attesting to the presence of more nucleating centers in the compatibilized blends. 


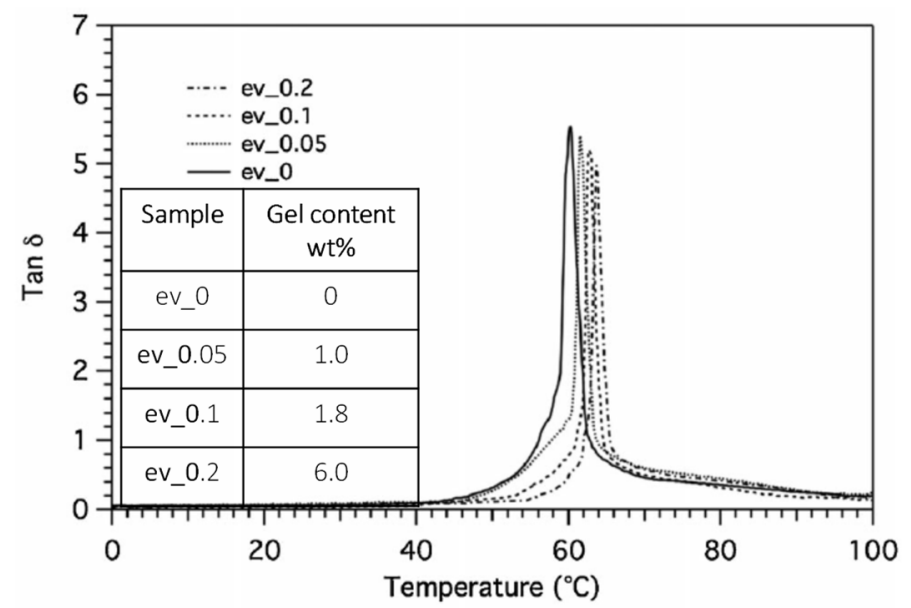

Figure 4. Tan $\delta$ as a function of DCP content; inset: gel content obtained for each sample. Reprinted (adapted) with permission from Ref. [95] Copyright 2015 Wiley.

More recently the properties of PLA/PBAT blend films treated with $0.1 \mathrm{wt} \%$ of bis(tertbutyl dioxy isopropyl) benzene (BIBP) were analyzed by changing the polymers ratio [96]. For this study, a PBAT copolymer with a slightly different composition was used: $45 \%$ BA-co- $55 \%$ BT. The mechanical properties, especially the tensile strength, were improved by BIBP and the best composition was $40 / 60 / 0.1$, for which the highest tear strength and sealing strength were observed. The authors underlined the complex mechanism of the process by considering that in addition to crosslinking, some less controllable reactions such as thermal degradation reactions with oxygen and hydrolysis, as well as esterification and transesterification may occur. However, the use of peroxide can be regarded as an economically balanced strategy to optimize the thermomechanical properties of PLA/PBAT blends, considering that the modification occurs in the melt by using a low amount of peroxide. The immiscibility between PBAT and PLA, also in the presence of BIBP, was proven by two glass transitions, although a small increase in both the $T_{\mathrm{g}}$ values was detected, thus attesting a higher entanglement concentration in the compatibilized blends. An increase in the PLA crystallinity in the presence of PBAT and compatibilizer was confirmed.

The use of transesterification catalyst has been studied to obtain comb-like copolymers acting at the interface in the toughening of PLA-based blends. Coltelli et al. [97] prepared PLA/PBAT 75/25 blends treated in the melt (by mixer) with $0.07 \mathrm{wt} \%$ of $\mathrm{Ti}(\mathrm{OBu})_{4}$ for different time and compared the properties of these blends with those of a mixture without the catalyst (Figure 5). The presence of $\mathrm{Ti}(\mathrm{OBu})_{4}$ allows formation of copolymers, as sketched in Figure 5A. In both formulations, the size of the dispersed phase was affected by the mixing time, and the stability of phase morphology was improved by the catalyst and optimized for a mixing time higher than $20 \mathrm{~min}$ (Figure 5B). This experimental evidence was correlated with the strain at break which increased by decreasing the dispersed phase domains and only in the presence of the catalyst and for longer blending time. This result showed that with smaller dispersed domains with rubber-like properties, the blend yield increases. The different trend observed for blends with and without $\mathrm{Ti}(\mathrm{OBu})_{4}$ suggested that a certain quantity of copolymer was formed (Figure 5A). SEC measurements revealed the presence of a low amount of copolymer $(0.65 \mathrm{wt} \%)$, which was enough to make the blend more compatibilized. The effect of $\mathrm{Ti}(\mathrm{OBu})_{4}$ was also tested on PLA/PBAT 70/30 blends (prepared by TS) by changing the content of transesterification catalyst [98] and finding remarkable improvement in comparison to PLA (Figure 5C). 

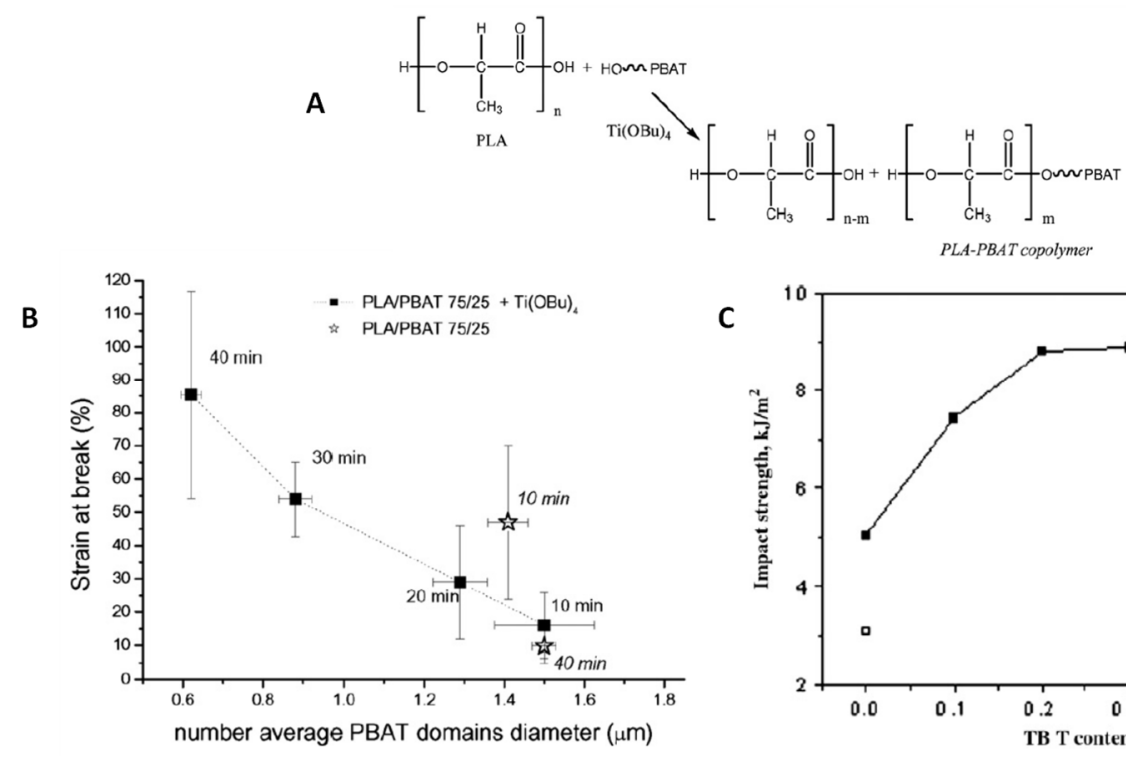

Figure 5. (A) Schematic representation of transesterification of PBAT with PLA; (B) strain at break as a function of PBAT domain decrease; $(\mathbf{C})$ variation of impact strength of PLA/PBAT with catalyst concentration versus pure PLA. Reprinted (adapted) with permission from Refs. [97,98] Copyright 2011 and 2012 Elsevier.

Mixtures of PLA and PBSA were compatibilized by using triphenyl phosphite (TPP, $2 \mathrm{wt} \%$ ) in the melt (by mixer) at different polymer ratio [99]. Again, morphological and mechanical behaviors were compared and the in situ formation of block copolymers acting as compatibilizers was assessed. SEM pictures clearly proved that the addition of TPP not only reduced the size of dispersed-phase, generating blends with a quite homogeneous morphology for low PBSA concentration, but it was also observed a different fracture surface. In particular, a smoothly debonded surface, indicating complete phase separation and brittle failure, was observed in the case of PLA/PBSA 50/50, while a more homogeneous surface with some ligament-like fibrils between phases undergoing ductile failure was found for PLA/PBSA/TPP 50/50/2 (Figure 6). During the reactive blending the chain-interchain reaction couples PLA and PBSA macromolecules, although undesired random copolymers are formed. Considering the reaction mechanism of TPP proposed by the authors, it appears that different copolymers are generated by reaction of TPP with $-\mathrm{OH}$ (preferentially reactive with TPP) and - $\mathrm{COOH}$ end groups. Two possible mechanisms were proposed in which $(\mathrm{A})$ the phosphite reacts with -OH end groups of the polymer chains and the phosphorus atoms result as building points of the extended and eventually branched polyester chains and (B) the substituted phosphite reacts with - $\mathrm{COOH}$ end groups of polymer chains and the phosphorus atoms are not included in the extended chains (see Figure 6). However, direct reaction of - $\mathrm{COOH}$ end groups with phosphite was not ruled out, thus generating benzoate ended-polyester chains. Despite the different mechanism of chain extension, intraphase and/or interchain reactions can occur leading to increased viscosity of the matrix and thus contributing to morphology modification by enhancing the deforming stresses during processing and avoiding the coalescence of dispersed phase. Compatibilization by TPP leads to partially miscible interface, as proven by the PLA $T_{g}$ decrease from 58 to $45^{\circ} \mathrm{C}$ for the PLA/PBSA 70/30 blend, at increasing TPP content from 0 to $6 \%$. However, a possible plasticizing effect of TPP could also not be ruled out. The $T_{\mathrm{g}}$ depression induced a high crystallinity in PLA upon non-isothermal crystallization [99]. 


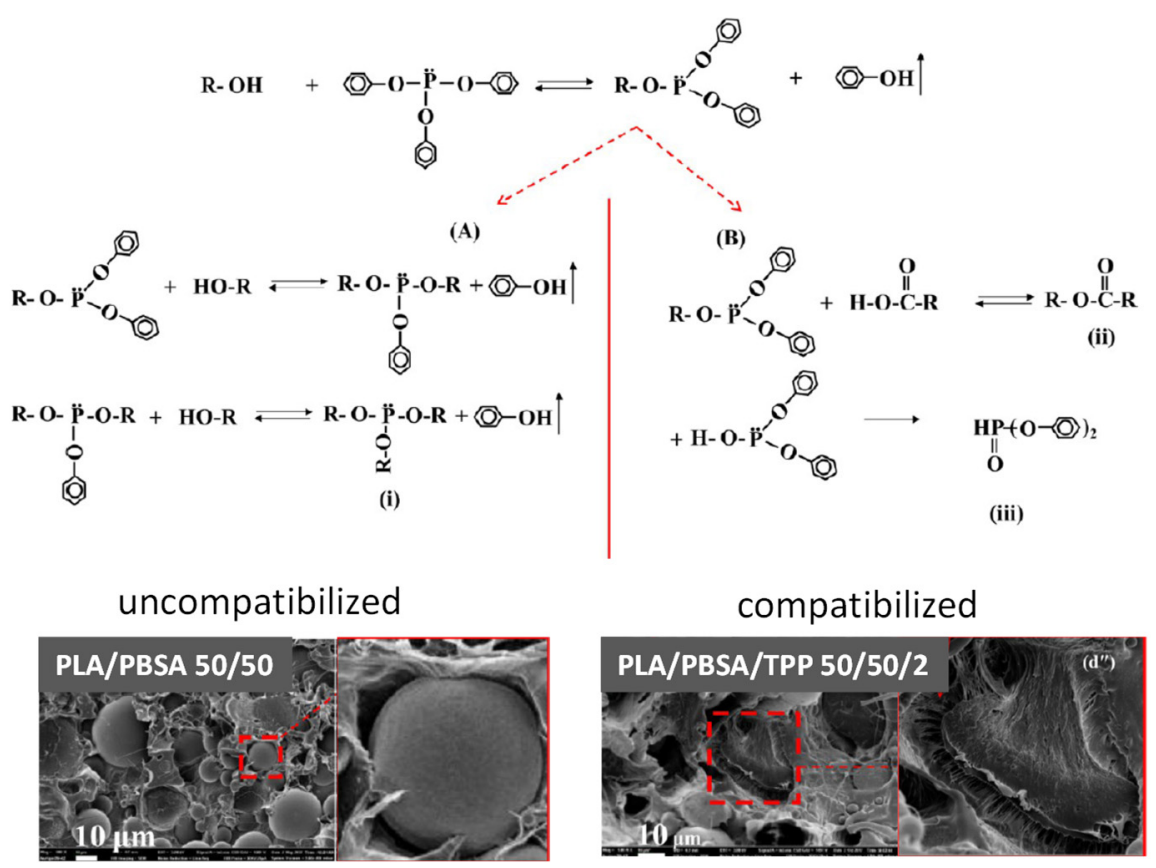

Figure 6. Schematic representation of reaction mechanisms between polyester chains ends and phosphite. SEM pictures (with enlargement of details of interface) for uncompatibilized and compatibilized blends. Reprinted (adapted) with permission from Ref. [99] Copyright 2013 American Chemical Society.

By optimizing the mixing time, the elongation at break was significantly improved without detriment of modulus values and overall, the impact strength raised from $6 \mathrm{KJ} / \mathrm{m}^{2}$ for PLA to 11 and $16 \mathrm{KJ} / \mathrm{m}^{2}$ for PLA/PBSA/TPP 70/30/2 and 90/10/2 respectively, confirming that TPP is a good reagent to enhance the compatibility of PLA/PBSA mixtures and then their toughness.

Among the family of chain extenders, the chemicals bearing epoxy functionalities have gained much more attention compared to other classes of reagents and have been mostly used [100-115]. In fact, as discussed in detail below, by operating in the melt the epoxy group can easily react with the carboxylic and hydroxyl end groups of polyesters, generating in situ copolymers with different structure/architecture which act as compatibilizers at the interface. The epoxy group can be added as a specific functionality of a third polymer and/or oligomer (that is the precursor of the compatibilizer) with different structures. Without any claim to be exhaustive, we report in Table 2 the most used polymers/reagents bearing the epoxy group and employed as chain extenders of PLA/PBAT or PLA/PBSA blends (T-GMA = Terpolymer of ethylene, acrylic ester and glycidyl methacrylate; EMA-GMA = Terpolymer of ethylene, methyl acrylate and glycidyl methacrylate; CESA = epoxy-functionalized PLA; EJ-400 = poly(propyleneglycl diglycidyl ethers); BETT = 1,3-bis(2,3 epoxypropyl)-s-triazine-2,4,6-trione; Joncryl = styrene acrylic ester, multifunctional oligomers (GMA); ECP = epoxy-cardanol prepolymer).

As a very general trend the use of these chain extenders improves the melt strength, thermal stability and mechanical features of the blends, passing from an island-and-sea morphology to a somewhat co-continuous phase for appropriate polyester ratios. The use of extenders results in a significant improvement in toughness up to super toughened blends [108,111-114]. 
Table 2. Mostly used precursors of compatibilizers containing epoxy functionalities, blends compositions and type of processing.

\begin{tabular}{|c|c|c|c|c|c|}
\hline Blends & Compatibilizer & Trade Name & Process $^{1}$ & Compositions & Ref. \\
\hline PLA/PBAT & T-GMA & Lotader ARKEMA & TS & $\begin{array}{c}\text { 90/10, 80/20, 70/30, } 60 / 40 \\
\text { T-GMA: } 1-10 \mathrm{wt} \%\end{array}$ & [100] \\
\hline PLA/PBAT & EMA-GMA & Nd ARKEMA & MM & $\begin{array}{c}90 / 10,82 / 10 / 0,75 / 10 / 8 \\
75 / 10 / 15,70 / 10 / 20 \\
\text { EMA-GMA: } 8-20 w t \%\end{array}$ & [101] \\
\hline PLA/PBSA & CESA & $\begin{array}{l}\text { CESA Extend OMAN } \\
\text { (Clariant) }\end{array}$ & MM & 70/30 CESA: $2 \mathrm{wt} \%$ & [102] \\
\hline PLA/PBAT & EJ-400 & EJ-400 (Jsi Co) & TS IM & 67/33 EJ-400: $10 w t \%$ & [103] \\
\hline PLA/PBAT & BETT & synthesized & MM & 50,750 BETT: 2 et5 & [104] \\
\hline $\begin{array}{l}\text { PLA/PBAT } \\
\text { PLA/PBSA }\end{array}$ & Joncryl & $\begin{array}{l}\text { Joncryl ADR-4368 } \\
\text { (BASF) }\end{array}$ & TS MM & $\begin{array}{c}80 / 20 \\
\text { ADR-4368: 0.25-1 wt } \% \\
\text { 60/40, 40/60 } \\
\text { ADR-4368: 0.3-0.6 wt } \% \\
\text { 90/10, 80/20, 70/30, 60/40 } \\
\text { ADR-4368: } 0.3-1.0 w \mathrm{w} \% \\
\text { 95/5, 90/10, 80/20 } \\
\text { ADR-4368: } 3 \mathrm{wt} \%\end{array}$ & $\begin{array}{l}{[105]} \\
{[106]} \\
{[107]} \\
{[108]} \\
{[109]}\end{array}$ \\
\hline PLA/PBAT & Joncryl & Joncryl ADR-4370S (BASF) & MM & $\begin{array}{c}80 / 20 \\
\text { ADR-4370S: } 1 \text { wt } \% \\
\text { 90/10, 80/20, 70/30,60/40 } \\
\text { ADR-4370S: } 0.75 \text { wt } \%\end{array}$ & $\begin{array}{l}{[110]} \\
{[111]}\end{array}$ \\
\hline PLA/PBAT & Joncryl & $\begin{array}{l}\text { Joncryl ADR-4370F } \\
\text { (BASF) }\end{array}$ & TS MM & $\begin{array}{c}50 / 50 \\
\text { ADR-4370F: 0.05-0.2 wt } \% \\
\text { 80/20, 60740, 40/60, 30/80 } \\
\text { ADR-4370F: 0.1 wt } \%\end{array}$ & $\begin{array}{l}{[112]} \\
{[113]}\end{array}$ \\
\hline PLA/PBAT & Joncryl & $\begin{array}{c}\text { Joncryl ADR-4368, 4380, } 4370 \\
\text { (BASF) }\end{array}$ & MM & $\begin{array}{c}80 / 20 \\
\text { ADR: } 0.1-0.15,0.2,0.3,0.5 w t \%\end{array}$ & [114] \\
\hline PLA/PBAT & $\mathrm{ECP}$ & $\begin{array}{c}\text { ECP Cardolite }^{\circledR} \\
\text { NC-514 } \\
\text { (Cardolite USA) }\end{array}$ & MM & $\begin{array}{c}\text { 80/20 } \\
\text { NC-514: } 3 w t \%\end{array}$ & [115] \\
\hline
\end{tabular}

${ }^{1}$ TS, twin screws extrusion; MM, mechanical mixing; IM, injection molding.

In particular, the Joncryl families, having the structure reported in Figure 7A, are considered especially reactive, because, owing to their multifunctionality, they are able to give rise to long chain branching aiming at improving the toughness and minimizing the effects of thermal and hydrolytic degradation of PLA (and or PBAT, PBSA) [110,116].

The reaction mechanism (Figure $7 \mathrm{~B}$ ) involves the opening of the epoxide ring by both carboxyl and hydroxyl end groups of PLA, PBAT or PBSA, as demonstrated by IR spectra, in which the characteristics signals related to deformation vibration of cyclic symmetric and asymmetric epoxide ring disappeared for all compositions [108,109]. It has been reported [108] that the epoxide group reacts preferentially with carboxyl end groups; moreover, the reaction occurs through the opening of the epoxide ring, followed by hydrogen abstraction from the carboxyl group generating a secondary hydroxyl group and an ester bond between the Joncryl and the polyester. Notably, the newly formed $-\mathrm{OH}$ group and the original -OH group compete to react with the epoxides (Figure 7B). As a result, branched and even cross-linked structures can be formed depending on the number of epoxide groups present in the Joncryl and the amount used during the reactive blending in the melt. 
A

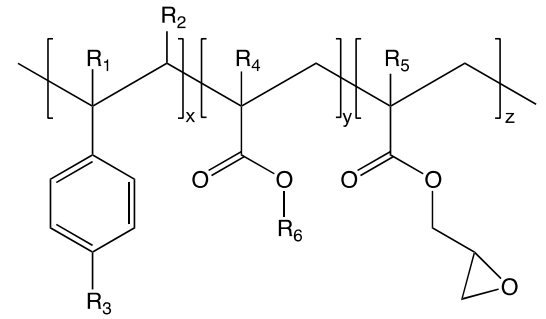

B

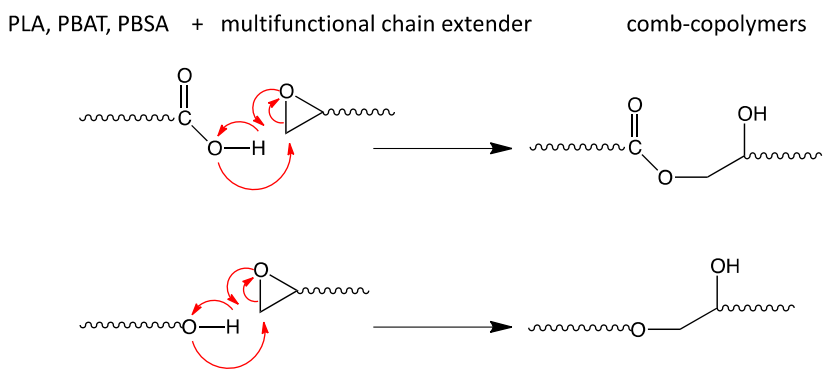

Figure 7. (A) Chemical structure of Joncryl where $x, y$, $z$ range between 1 and $20 ; R_{1}, R_{2}, R_{3}$ and $R_{4}$ are $\mathrm{H},-\mathrm{CH}_{3}$ or higher alkyl group; $\mathrm{R}_{6}$ is an alkyl group; (B) schematic representation of reactions between the end groups of polyesters and the epoxy ring of chain extenders.

PLA and PBAT (or PBSA) were combined by Joncryl forming the effective double/graft copolymers PLA-PBAT or PLA-PBSA with different architecture depending on content and number of epoxy functionalities [105-114]. The in situ copolymers formed at the interface are responsible for the enhanced compatibility between the two phases; PLAPLA homojunctions (as well as PBAT-PBAT and PBSA-PBSA) minimize the degradation effects onto the thermomechanical features of the blends and have a significant effect on both deformation mechanism and break-up conditions owing to viscosity changes. The addition of Joncryl leads also to a significant reduction of the average size of the dispersed phase [106] for blend compositions generating PLA as matrix, and to an enhancement of adhesion between the phases with reduction of debonding phenomenon for co-continuous morphologies by decreasing the content of PLA [112]. In PLA/PBSA blends prepared with addition of increasing amount of Joncryl [108], the $T_{\mathrm{g}}$ of the two polymeric components was found not to change, thus confirming the immiscibility also in the presence of the compatibilizer. Conversely, crystallization in the blend turned out to be more hindered, although the addition of Joncryl to pure PLA and PBSA induced crystallization at higher temperatures and higher crystallinity was obtained, with the branching points acting as heterogenous nuclei. However, due to restricted chain mobility, in the presence of Joncryl, thinner and more imperfect PLA crystals grew [108].

In agreement with such results concerning the morphological behavior, the addition of Joncryl improved the mechanical properties: the elongation at break increased from $23.5 \%$ to $410.3 \%$ and the notched Izod impact strength from 7.5 to $33.4 \mathrm{KJ} / \mathrm{m}^{2}$ by increasing the content of Joncryl. The chain extender with higher content of epoxy functionality produced the higher increase in $M_{\mathrm{w}}$ and more effective tensile properties [114]. In addition, the thermal stability of the blends was improved owing to partial cross-linking and formation of heterogeneous nucleation causing, in some cases, a decrease in oxygen and water vapor permeability [109]. These results were reached for all the blends composition, opening the way to prepare materials suitable for flexible functional packaging.

To better meet the biodegradability and compostability requirements and to make use of fully biobased components, an epoxy-cardanol prepolymer (ECP) and epoxidized (ECSO) or maleinized cottonseed (MCSO) oil were recently used as compatibilizers and chain extenders and the thermomechanical results were compared with those obtained with the petroleum-based Joncryl family. PLA/PBAT 80/20 blends added with different content of these biobased additives produced a remarkable increase in elongation at break, 
without compromising the other mechanical resistance properties and the ultimate polymer biodegradability (Table 3). The really good results achieved especially by employing MCSO take advantage of the fact that the additive was derived from agricultural waste, thus providing chemicals suitable for biobased packaging industry $[115,117]$.

Table 3. Mechanical features of PLA/PBAT $80 / 20$ blends treated with different biobased chain extenders (from Refs [115,117]).

\begin{tabular}{ccccc}
\hline Additive & $\begin{array}{c}\text { Content } \\
(\mathbf{w t} \mathbf{\%})\end{array}$ & $\begin{array}{c}\text { Young's Modulus } \\
\mathbf{( M P a )}\end{array}$ & $\begin{array}{c}\text { Tensile Strength } \\
\mathbf{( M P a )}\end{array}$ & $\begin{array}{c}\text { Elongation at } \\
\text { Break (\%) }\end{array}$ \\
\hline none & - & $1700-2100$ & $29-33$ & $52-60$ \\
ECP & $1,3,5$ & $2100-1600$ & $31-29$ & $150-190$ \\
ECSO & $1,7.5$ & $2400-1900$ & $60-40$ & 65 \\
MCSO & $1,7.5$ & $3000-2400$ & $60-40$ & $75-125$ \\
Joncryl & 1 & 2200 & $26-37$ & 75 \\
\hline
\end{tabular}

The use of maleinized derivatives has been investigated by grafting maleic anhydride (MAH) onto PLA [118], or by using functional polymers containing the succinic anhydride [119]. Again, it was proved that the functional groups react with the -OH groups of PLA and/or PBAT promoting the interface bonding between the polyesters and thus a non-negligible effect on toughening.

\section{PLA/PBAT and PLA/PBSA Blend Nanocomposites: Preparation and Characterization}

Incorporation of solid nanoparticles as a third component in immiscible polymer blends has great influence on the morphology and interfacial properties; knowledge of nanoparticles localization is the key parameter for addressing materials formulation towards some desired features. Importantly, nanoparticle aspect ratio, polymer filler interactions, surface tension, viscosity ratio, blending sequences, mixing time and kind of processing play a fundamental role in the morphology development and thus in the ultimate properties of the blends. Recently the use of nanosized inorganic fillers as morphology stabilizers has been considered for tuning and optimizing effects mainly due to particles' localization at the interphase, especially in co-continuous phases. In fact, depending on surface interactions, the nanoparticles could be localized at the interface between the dispersed and continuous phases acting as physical agents, avoiding the coalescence of droplets and also stabilizing the morphologies against further processing steps.

In this section, we report some examples of nanocomposites based on PLA/PBAT and PLA/PBSA blends by dispersing 2D (nanoclay), 1D (multiwalled carbon nanotubes) and OD (nanosilica) nanostructured systems.

Among the layered nanoparticles, nanoclays and especially organo-modified nanoclays have been extensively studied and both the exfoliation degrees and the localization of platelets between the phases by changing the inorganic content, or the kind of organophilic surfactants or the polymer ratios have been investigated to explain their effects on the thermal, mechanical, rheological and barriers features. PLA/PBAT- and PLA/PBSA-based nanocomposites were prepared and studied by dispersing in polymer blends with different composition cationic and anionic nanoclays modified with organophilic surfactants (Table 4) [81,120-134].

The general results evidence that the dispersion of clay nanoplatelets reduces the dimensions of the dispersed phase by decreasing the diameter of the droplets, which becomes smaller in the presence of nanoclay. Clay platelets play the role of compatibilizer and suppress the coalescence generating a finer droplet morphology compared to the corresponding blends. Kamal et al. [132] estimated the wetting coefficient from the interfacial energy and found that clay platelets were preferentially located at the interface for PBSA content greater than $25 \mathrm{wt} \%$ with small amount located within PLA and PBSA phases, as also proved by SEM and TEM investigations. Lower content of PBSA enabled the localization of clay platelets in PBSA owing to its lower viscosity at processing temperatures. 
By increasing the content of PBSA (50/50 composition) an evident change in morphology from co-continuous (in the blend) to elongated droplets (in the nanocomposite) was observed. This result is due to the change in viscosity ratio caused by the incorporation of clay platelets whose large amount is located at the interface, thus creating a polymer-particle and particle-particle interfacial network-like structure. The incorporation of clay platelets produced a remarkable improvement of mechanical properties particularly for optimized content of nanoclay: for example, Ojijo et al. [123] found really good behavior for the $70 / 30$ blend containing $2 \mathrm{wt} \%$ of Cloisite 20A. The presence of the nanoclay was found to modify the thermal properties of PLA/PBSA + Cloisite 20A nanocomposites, as a function of nanofiller location and amount. Different clay locations were identified: (i) the nanofiller was situated within PBSA when its percentage was lower than $1 \mathrm{wt} \%$, (ii) the nanofiller was located at the interface and within PLA and PBSA when its amount was around $2 \mathrm{wt} \%$, (iii) the nanofiller resided within PLA if present with percentage higher than $4 \mathrm{wt} \%$. For nanoclay located at the interface, the absorption of both the polymers on its surface was found to hinder the crystallization process [123].

Table 4. Type of nanoclay and blends composition used for preparation of PLA/PBSA or PLA/PBAT nanocomposites.

\begin{tabular}{|c|c|c|c|c|}
\hline Blends & Nanoclay ${ }^{1}$ & Modifier & Chain Extender & Ref. \\
\hline $\begin{array}{c}\text { PLA/PBSA } \\
75 / 25,50 / 50,70 / 30,25 / 75\end{array}$ & $\begin{array}{l}\text { MMT } \\
\text { Cloisite 30B } \\
\text { (C30B) }\end{array}$ & $\begin{array}{c}\text { Methyl tallow } \\
\text { bis(2-hydroxiethyl) quaternary } \\
\text { ammonium salt }\end{array}$ & - & [120-122] \\
\hline $\begin{array}{c}\text { PLA/PBSA } \\
90 / 10,80 / 20,70 / 30\end{array}$ & $\begin{array}{l}\text { MMT } \\
\text { Cloisite 30A } \\
\text { (C30A) }\end{array}$ & $\begin{array}{c}\text { Dimethyl dehydrogenated } \\
\text { tallow quaternary } \\
\text { ammonium salt }\end{array}$ & - & {$[121,123,126]$} \\
\hline $\begin{array}{l}\text { PLA/PBSA } \\
80 / 20\end{array}$ & $\begin{array}{c}\text { LDH } \\
\text { SaLDH }\end{array}$ & Stearic acid (surface coated) & - & [124] \\
\hline $\begin{array}{l}\text { PLA/PBSA } \\
80 / 20\end{array}$ & $\begin{array}{c}\text { MMT } \\
\text { Unmodified }\end{array}$ & $\mathrm{Na}+$ & - & [126] \\
\hline $\begin{array}{c}\text { PLA/PBAT } \\
80 / 20,70 / 30,60 / 40,50 / 50\end{array}$ & $\begin{array}{l}\text { MMT } \\
\text { Cloisite 30B } \\
\text { (C30B) }\end{array}$ & $\begin{array}{c}\text { Methyl tallow } \\
\text { bis(2-hydroxiethyl)quaternary } \\
\text { ammonium salt }\end{array}$ & - & [125-127] \\
\hline $\begin{array}{l}\text { PLA/PBAT } \\
80 / 20\end{array}$ & $\begin{array}{c}\text { MMT } \\
\text { Unmodified }\end{array}$ & $\mathrm{Na}+$ & - & [126] \\
\hline $\begin{array}{l}\text { PLA/PBAT } \\
70 / 30\end{array}$ & $\begin{array}{c}\text { MMT } \\
\text { (MMT-RDP) }\end{array}$ & $\begin{array}{l}\text { resorcinol diphenyl phosphate } \\
\text { (surface coated) }\end{array}$ & - & [128] \\
\hline $\begin{array}{c}\text { PLA/PBAT } \\
75 / 25,50 / 50,25 / 75\end{array}$ & $\begin{array}{c}\text { MMT } \\
\text { (organomodified) }\end{array}$ & $\begin{array}{c}\text { Gum rosin and stearic acid } \\
\text { (adsorbed starting from } \\
\text { organomodified clay) }\end{array}$ & - & [129] \\
\hline $\begin{array}{l}\text { PLA/PBAT } \\
90 / 10\end{array}$ & $\begin{array}{c}\text { MMT } \\
\text { (organomodified) }\end{array}$ & $\begin{array}{l}\text { Methyl tallow } \\
\text { bis(2-hydroxiethyl)quaternary } \\
\text { ammonium salt }\end{array}$ & PLA g-MAH & [130] \\
\hline $\begin{array}{l}\text { PLA/PBAT } \\
75 / 25\end{array}$ & $\begin{array}{l}\text { MMT } \\
\text { Cloisite 30B } \\
\text { (C30B) } \\
\text { MMT }\end{array}$ & $\begin{array}{c}\text { Methyl tallow } \\
\text { bis(2-hydroxiethyl)quaternary } \\
\text { ammonium salt } \\
\text { Methyl tallow }\end{array}$ & GMA & [131] \\
\hline PLA/PBAT & $\begin{array}{l}\text { Cloisite 30B } \\
\text { (C30B) }\end{array}$ & $\begin{array}{l}\text { bis(2-hydroxiethyl)quaternary } \\
\text { ammonium salt }\end{array}$ & MAH + peroxide & [132] \\
\hline $\begin{array}{l}\text { PLA/PBSA } \\
90 / 10,80 / 20\end{array}$ & $\begin{array}{l}\text { MMT } \\
\text { (MEE) }\end{array}$ & $\begin{array}{l}\text { Dipolyoxy ethylene alkyl } \\
\text { methyl ammonium salt }\end{array}$ & TPP & [81] \\
\hline $\begin{array}{c}\text { PLA/PBSA } \\
90 / 10,80 / 20,70 / 30\end{array}$ & $\begin{array}{l}\text { MMT } \\
\text { Cloisite 30B } \\
\text { (C30B) }\end{array}$ & $\begin{array}{c}\text { Methyl tallow } \\
\text { bis(2-hydroxiethyl)quaternary } \\
\text { ammonium salt }\end{array}$ & CESA & [133] \\
\hline $\begin{array}{l}\text { PLA/PBAT } \\
45 / 55\end{array}$ & $\begin{array}{l}\text { MMT } \\
\text { Cloisite 30A } \\
\text { (C30a) }\end{array}$ & $\begin{array}{c}\text { Dimethyl dehydrogenated } \\
\text { tallow quaternary } \\
\text { ammonium salt }\end{array}$ & $\begin{array}{c}\text { Joncryl } \\
\text { ADR-4368 }\end{array}$ & [134] \\
\hline
\end{tabular}

\footnotetext{
${ }^{1} \mathrm{MMT}=$ montmorillonite; $\mathrm{LDH}=$ layered double hydroxide.
} 
Recently, interesting results have been obtained by using organo-modified LDH: for low content of SaLDH (a layered double hydroxide surface-coated with stearic acid) the particle are primary loaded in the PBSA dispersed phase having minor viscosity; however, by increasing the content of SaLDH particles, their concentration and even their dispersion in the PLA continuous phase improved. The maximum elongation at break was reached for $0.5 \mathrm{wt} \%$ of nanoclay. This composition also showed improved thermal stability and barrier properties against oxygen transmission [124].

Similar results have been obtained for PLA/PBAT-based nanocomposites [125-129]. Clay platelets were dispersed in PBAT or PLA phases depending on composition and type of organoclay, with a large portion of lamellae located at the interface. The incorporation of the clay in the nanocomposites reduced the dimension of the dispersed phase, whose domains or droplets were finer compared to the corresponding blends. Moduli values also improved, but a general detriment of the elongation was observed [125]. Hyun at al [126] correlated the rheological properties and storage modulus values with the morphology of nanocomposites by dispersing increased amounts of different nanoclays in PLA/PBAT and PLA/PBSA blends. They aimed to study the "compatibilization" effect of different nanofillers. As proved by XRD and TEM analysis, the C30B showed the best dispersion and the largest increase of interlayer distance with a great mechanical response, due to the chemical affinity of surfactant containing - $\mathrm{OH}$ functionalities, which promotes polymer chains intercalation. C20A also showed good compatibilization owing to its large starting interlayer distance. Both the organo-clays were located at the interface between the matrix and the dispersed phase. Instead, unmodified MMT was located in the dispersed phase and its composites showed poor intercalation and lower mechanical properties compared to the corresponding blend.

Kamal et al. [127] prepared two PLA/PBAT/Cloisite 30B nanocomposites with different compositions (i.e., $75 / 25 / 1$ and $75 / 25 / 5$ ) through three strategies of mixing, and then performed a thorough morphological analysis of the obtained samples. The mixing procedures were as follows: the nanoclay was added to the 75/25 PLA/PBAT blend (method S1); the nanoclay was first mixed with PLA and then the PLA/nanoclay nanocomposite was mixed with PBAT (method S2); the nanoclay was mixed with PBAT and then the resulting composite was mixed with PLA (method S3). For both nanoclay concentrations (1 and $3 \mathrm{wt} \%$ ), the PBAT average droplet diameter decreased compared to the pure blend (Table 5). In the case of the composite containing $1 \mathrm{wt} \%$ nanoclay, morphological analysis showed that the clay nanoparticles were located at the interface regardless of the mixing method used; in other words, even if the nanoclay was initially dispersed in the PLA or PBAT as a pure polymer, the nanoparticles transferred to the interface. Cloisite 30B has a fairly similar affinity to both the PLA and PBAT phases, therefore it tends to locate at the interface.

Table 5. Average diameter of the droplet, Dv (data with permission from Ref. [127] Copyright 2016 Elsevier).

\begin{tabular}{cc}
\hline Sample and Mixing Strategy & $\begin{array}{c}\text { Dv } \\
(\mathbf{m})\end{array}$ \\
\hline PLAT/PBAT 75/25 & 1.3 \\
PLA/PBAT/C30B 75/25/1 method S1 & 0.75 \\
PLA/PBAT/C30B 75/25/1 method S2 & 0.85 \\
PLA/PBAT/C30B 75/25/1 method S3 & 0.70 \\
PLA/PBAT/C30B 75/25/5 method S1 & 0.65 \\
PLA/PBAT/C30B 75/25/5 method S2 & 0.75 \\
PLA/PBAT/C30B 75/25/5 method S3 & 0.35 \\
\hline
\end{tabular}

In blend composites with the higher content of nanoclay (5 wt\%) the PBAT phase dimension was much smaller for the blends prepared by method S3, suggesting that the primary inclusion of platelets in the PBAT phase is more efficient in stabilizing the interface by hindering the coalescence phenomenon. Concerning the localization of lamellae, the 
method S1 provided inclusions in the PLA matrix and at interface, method S2 enabled the localization of nanoclay in the PLA matrix and slightly at the interface, while in method S3 the nanoparticles were mostly arranged at the interface (Figure 8). It seems that for high loading of nanofiller the increased viscosity of the PLA matrix partially hindered the particles' migration from one phase to another, and localization at the interface was not as effective. Moreover, PBAT allowed migration with a higher concentration of platelets at the interface, justifying the decrease in PBAT droplets diameter.
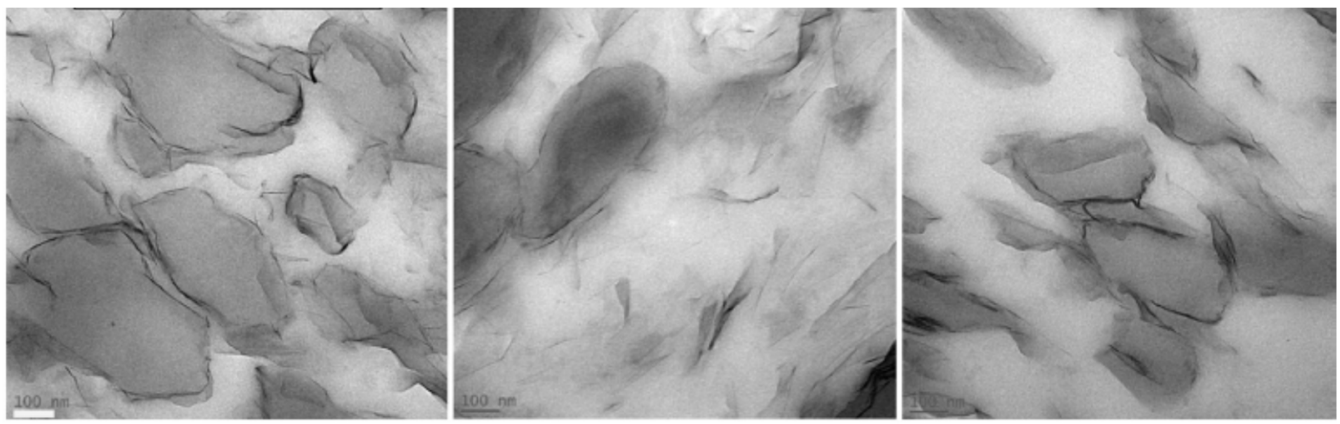

Figure 8. TEM images showing the localization of $5 \mathrm{wt} \%$ C30B in PLAT/PBAT 75/25-based nanocomposites prepared with different strategies (from left to right, methods S1, S2, S3). Reprinted (adapted) with permission from Ref. [127] Copyright 2016 Elsevier.

Interesting results have been collected by using nanoclays modified with functional molecules such as surfactants or more environmentally friendly surface modifiers. Based on the assumption that biodegradable polymers should contain only environmentally safe additives and that no toxic substances should be released during biodegradation, Guo et al. [128] used MMT surface-coated with resorcinol diphenyl phosphate, which is safer than quaternary ammonium salts of Cloisite. Although the impact strength of PLA/PBAT blends was negatively affected by the dispersion of such modified clay, the overall morphology behavior was comparable to that of nanocomposites having the same polymer ratio and obtained by incorporation of $\mathrm{C} 30 \mathrm{~B}$. In another example, rosin gum was adsorbed onto organo-modified nanoclay and successfully dispersed in PLA/PBAT blends at different polymer ratios. In addition to achieving good dispersions, the nanocomposites showed strong antimicrobial activity against Gram-positive and Gram-negative bacteria [129].

Several authors have investigated the effect of chain extenders and reactive agents on the dispersion of clay and the final properties of nanocomposites. PLA grafted with MAH (PLA-g-MAH) was successfully used to remarkably increase the elongation at break of nanocomposites containing organo-MMT [130]. GMA [131] and MAH with peroxide [132] were used to impact the thermomechanical features, but no details were reported concerning the clay dispersion. PLA/PBSA blends were added with TPP and two different organo-modified clays (MEE and C20A see Table 4) [81]. Both the nanoclays were dispersed at the nanoscale level, showing intercalated morphologies with the highest concentration of clay particles residing at the interphase of PLA and PBSA domains. MEE contains functionalities able to play a role in catalyzing the chain extension coupling reactions, which was only partially effective owing to side reactions. Instead, C20A and TPP resulted in higher chain extension that provoked remarkable thermal stability of obtained nanocomposites with higher toughness compared to pure PLA. In addition, both the clays imparted oxygen and water vapor barrier properties particularly in the case of nanocomposites, with MEE having a higher aspect ratio. CESA [133] and Joncryl [134] were also used. In the first case, the effect of the use of TS processing at different rotation per minute on morphology and chain-extension/degradation effectiveness was investigated: optimized features were obtained for 70/30 polymers ratio and high screw speed, even though the role of reagents and the mechanism of reaction was not fully investigated. In the latter, the authors reported that chain extension was partially hindered by MMT even though the nanocomposite with 
Joncryl showed fine morphology and resulted in a lower amount of evolved $\mathrm{CO}_{2}$ during soil burial owing to the increase of molecular weight.

Multiwalled carbon nanotubes (MWCNT) were used as nanofillers to impart electrical conductivity to PLA/PBAT and PLA/PBSA blends. Ko et al. [135] studied the morphology of PLA/PBAT/MWCNT nanocomposites by changing the polymer ratio and keeping constant the amount of MWCNT ( $2 \mathrm{wt} \%$ ). It was noticed that MWCNT aggregates were preferentially located in the PBAT phase, independently of morphology addressed by the polymer ratio: the dispersed MWCNT-filled PBAT phase appeared as droplets for low PBAT concentrations, while it was mostly co-continuous with increasing PBAT content. The authors supposed that the higher affinity of MWCNT for PBAT could be related to the chemical structure of the PBAT, which has aromatic functionalities in the backbone more interactive with MWCNT and to the lower viscosity of PBAT compared to that of PLA. More recently, Eguiazàbal et al. [136] clearly confirmed by TEM analysis that MWCNT preferentially located in PBAT dispersed phase, particularly for low content of the minor component (Figure 9).
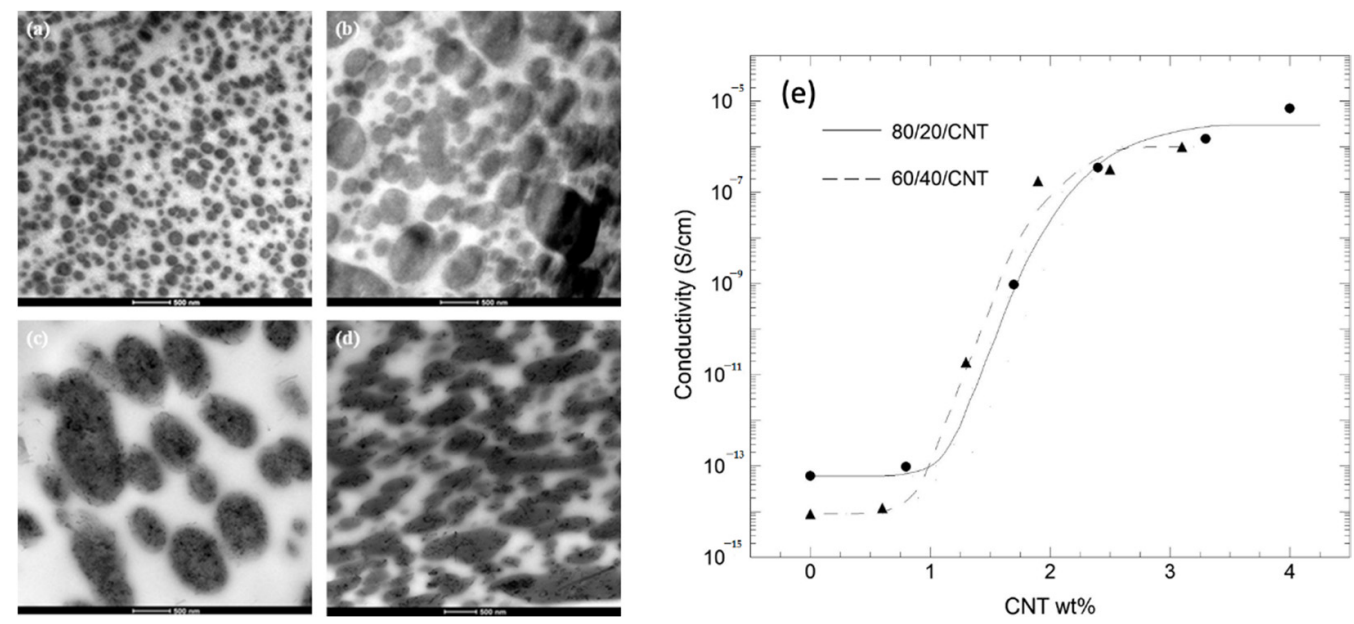

Figure 9. (a,b) TEM micrographs of 80/20 and 60/40 PLA/PBAT blends and (c,d) their corresponding nanocomposites with 2.4 and $1.8 \mathrm{wt} \%$, respectively, of MWCNT; (e) conductivity as a function of MWCNT. Reprinted (adapted) with permission from Ref. [136] Copyright 2017 Elsevier.

The MWCNTs appeared aggregated even at the lowest MWCNT content but this effect became more pronounced as the MWCNT content increased. However, in the PLA60/PBAT40/MWCNT composites, a significant number of individual nanotubes along with some small aggregates were observed (Figure 9d) with several less aggregated particles residing in the PLA matrix.

Figure 9 also shows that the morphology of the unfilled PLA/PBAT blend changed upon the addition of CNTs, whatever the composition. In the case of the 80/20 PLA/PBAT composition (Figure $9 \mathrm{a}, \mathrm{c}$ ), there was a clear increase in the size of the dispersed CNT-filled PBAT particles (Figure 9b,d). The increase in viscosity of the minor phase caused by filler embedding favored the coalescence and larger droplets were formed passing from almost spherical to slightly elongated. In particular, the dispersed PBAT particles in the 80/20/2.4 PLA/PBAT/MWCNT composition were almost touching each other, forming a percolation path justifying the values of conductivity which was increased with MWCNT independently of the dimension of droplets and content of PBAT.

Kamal et al. [137] investigated the properties of PLA/PBSA/MWCNT 66.5/28.5/5 wt $\%$ nanocomposite by changing the melt mixing procedure: MWCNT was firstly dispersed in the PLA following the addition of PBSA (sample 1); MWCNT was firstly dispersed in the PBSA following the addition of PLA (sample 2); PLA and PBSA were pre-compounded following the incorporation of MWCNT (sample 3); the PLA, PBSA and MWCNT were simultaneously mixed (sample 4). SEM analysis showed that MWCNT particles were in 
the PBSA phase despite they were previously dispersed in the PLA phase, proving that during the subsequent melt mixing they can migrate from the continuous (PLA) to the dispersed (PBSA) phase.

Favis's group $[138,139]$ studied the effect of the mixing procedure on the localization of silica nanoparticles and then on the morphology and mechanical properties of PLA/PBAT nanocomposites having different PLA/PBAT ratios. In particular, when nanosilica was added to PLA/PBAT melt, the nanoparticles were selectively located into the PBAT dispersed phase, while if the nanoparticles were premixed with the PLA matrix and then mixed with the PBAT, a particle assembling at the interface was observed. This latter mixing methodology was then used to investigate the effect in interfacial localization of silica nanoparticle on PLA/PBAT 70/30 blend near the co-continuity (70/30) and on cocontinuous PLA/PBAT 50/50 blend. Interestingly, for nanocomposite with 70/30 polymer ratio, the $1 \mathrm{wt} \%$ nanosilica particles, localized at the interface, reduced the diameter of the dispersed phase showing a finer dispersion, but by increasing the content of nanosilica up to $3 \mathrm{wt} \%$ a morphology change from matrix-dispersed phase to the highly continuous structure was highlighted (Figure 10). In the case of PLA/PBAT 50/50 co-continuous blend, a clear assembling of particles at the interface was observed; the nanosilica here completely hindered the phase coarsening upon annealing, as conversely occurred for the neat blend. Rheological data confirmed this evidence which seemed to improve the mechanical features of nanocomposites as reported in Figure 10d.
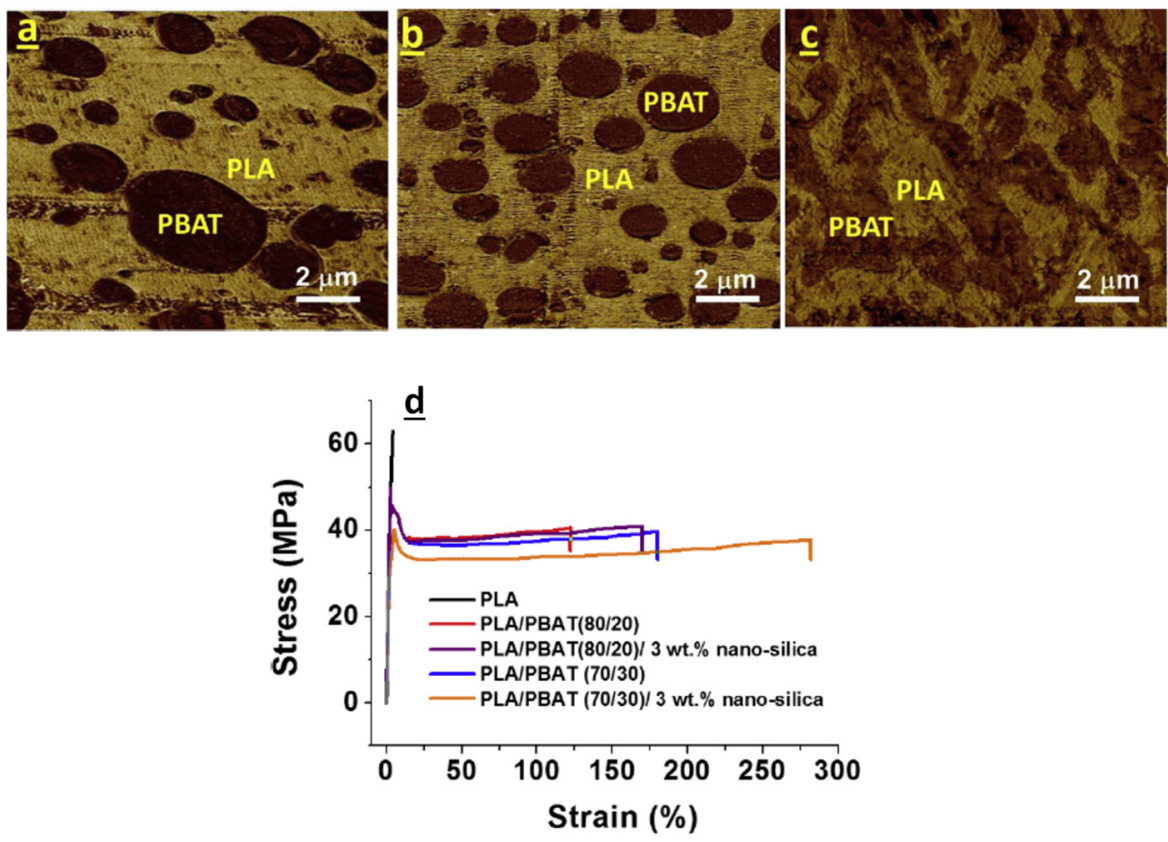

Figure 10. AFM of PLA/PBAT 70/30 (a); PLA/PBAT/nanosilica 70/30/1 (b); PLA/PBAT/nanosilica $70 / 30 / 3$ (c); stress-strain measurements for samples with and without nanosilica (d) Rheological data. Reprinted (adapted) with permission from Ref. [139] Copyright 2016 Elsevier.

Nanoparticles, which are non-permeable to gas molecules, generally improve the barrier properties, because they create a tortuous path for diffusion. Thus, addition of C20A and C30B to PLA/PBSA blends, for example, was found to reduce oxygen permeability [81]. In addition, water diffusion can be governed by the presence of nanoparticles: increase in water resistance can be obtained, with consequent reduction in hydrolytic degradation rate, in case of hydrophobic nanoparticles. Conversely, hydrophilic nanoparticles can speed up water absorption and hydrolytic degradation rate [140]. 


\section{Biodegradation of PLA, PBAT, PBSA and Their Blends}

Studies on polymers biodegradability outline that there is a relationship between the chemical structure of polymeric substrates and their mineralization rates. Polymer biodegradability is connected with polymer crystallinity, crosslinking and molecular weight. Polymers with a lower crystallinity degree and with lower elastic modulus are generally the ones with the highest degradation rate [141-145]. Biodegradability is promoted by lower molar mass and the presence of terminal hydroxyl or acyl functional groups, which can favor metabolic processes [146-148]. In addition, selection of proper additives, in particular plasticizers and fillers, can significantly speed up the biodegradation of polymerbased materials $[149,150]$.

PLA is known to meet the requirements for industrial compostability, according to the EU standard EN 13432 "Requirements for packaging recoverable through composting and biodegradation-Test scheme and evaluation criteria for the final acceptance of packaging" (2000). This standard addresses even the thickness of the samples: in industrial composting conditions PLA is certified up to $3000 \mu \mathrm{m}$ thickness, while PBAT up to $120 \mu \mathrm{m}$.

In the first step of PLA degradation, the ester bonds are cleaved hydrolytically with production of low molar mass oligomers. When the molar mass gets lower than about 20,000 g/mol, PLA becomes water soluble [151]. The ester bond hydrolysis is an abiotic process catalyzed by the carboxylic acid end groups of PLA, whose $\mathrm{pKa}$ (approximately 3 ) is lower than that of other carboxylic acid groups (about 4.5-5) [152]. The abiotic hydrolysis corresponds to the rate limiting step under composting conditions [153]. The second step consists of biotic degradation catalyzed by microorganisms, with production of metabolic end compounds, such as carbon dioxide and water, and partial conversion of organic carbon into biomass [154]. Mineralization of PLA in industrial compost proceeds efficiently due to the combined effects of hydrolysis and microbial activity, since the elevated temperatures encountered during composting, exceeding $50{ }^{\circ} \mathrm{C}$, accelerate the hydrolysis process [155]. When composting is done at domestic level (home composting), the temperatures are not high as in industrial composting. Thus PLA, which needs high temperature and high moisture content to start hydrolysis, does not meet the requirements to achieve the certifications for home composting or soil biodegradability. Several studies have demonstrated that PLA biodegradation under composting conditions increases when layered silicates are incorporated [156-158]. A possible reason for this increase is the hydrophilicity of the clay, which facilitates water diffusion in the polymer matrix promoting the hydrolysis step [159].

The aromatic fraction of commercial PBAT provides useful physical properties, whereas the aliphatic chain portions promote its degradation in several conditions, including soil degradation, without need for temperature control [42]. In this case, PBAT biodegradation passes through hydrolysis induced by the enzymatic action of microorganisms such as fungi, bacteria and algae present in the natural environment, during which the non-crystalline BA portion degrades faster than the semicrystalline BT structure [160]. Hydrolytic degradation involves cleavage of ester linkages and reaction between water and the carbonyl groups located in the proximity of the benzene rings.

The biodegradability in soil of the blends PLA/PBAT was found to be slower than that of pure PBAT, due to the presence of PLA [161]. A study on the biodegradation in soil of PLA/PBAT blends compatibilized with chain extender showed that the functional groups of the chain extender reacted with the groups produced during the degradation, thus causing biodegradation delay [162]. The biodegradation of PLA/PBAT blends in freshwater with muddy sediment was even found to be slower than that of the two pure polymers [163]. The presence of silver-loaded kaolinite, as filler, in PLA/PBAT blends compatibilized with tetrabutyltitanate caused a delay in the material biodegradation in compost [164]. The reason was connected with a higher crystallinity induced by the filler, acting as barrier to water adsorption and hydrolysis.

PBSA is a highly biodegradable polymer [14,69], certified for degradability in compost, home compost and soil, because both films and molded items significantly biodegrade 
within a few months in soil, sea water and water enriched with activated sludge [165]. Unfortunately, very limited literature on biodegradability of PBSA/PLA blends can be found. Enzymatic degradation rate was investigated for neat PLA, PBSA and their blends [166]. The degradation rate of neat PBSA was higher than that of neat PLA, and the presence of PBSA increased the blend degradation rate. The incorporation of some nanofillers (for example C20A, i.e., MMT modified with dimethyl dehydrogenated tallow quaternary salt) led to enhanced degradation rate, whereas, in the presence of $\mathrm{C} 30 \mathrm{~B}$, the degradation rate decreased. The different behavior was ascribed to different dispersion of the intercalated nanoclays and different effect of the nanoparticles on the total crystallinity.

Degradation in soil landfilled conditions was investigated for yarns of PLA/PBSA blends braided with jute fibers [167], but the test lasted only 28 days, with the result that the biodegradation was only initial. Thus, an extensive study on mineralization of PLA/PBSA blends in different medium, such as industrial compost, home compost, soil, water is still lacking.

\section{Applications of PLA/PBSA and PLA/PBAT Blends and Nanocomposites}

Research on PLA based materials has increased markedly in the last years, with the aim to improve the properties of this biopolymer, and, at the same time, reduce its cost. The main goal is to increase PLA ductility and reduce its brittleness. Various additives, compatibilizers, comonomers have been incorporated to PLA, as well as blending with a different polymer or biopolymer. PLA based blends are generally utilized as films for packaging and agricultural applications, but also for medical applications, due to their thermal, mechanical and biodegradability properties $[4,8]$. Similarly, PLA/PBSA and PLA/PBAT blends are produced and investigated mainly for packaging and food service applications [7].

One type of packaging widely used for fresh-cut and ready-to-eat products is peelable lidding film sealed on containers $[168,169]$. Although a PLA lidding film can be easily sealed on PLA container, and easily opened, and has the proper gas barrier properties, the intrinsic brittleness of the polymer easily tears or breaks during peeling [168]. As discussed above, the brittleness of PLA can be improved by blending with both PBAT and PBSA.

For PLA/PBAT blends, besides brittleness, it was also found that haze and peel strength are affected by blend composition [170]. An optimum PLA/PBAT ratio of $80 / 20 \mathrm{wt} / \mathrm{wt}$ was identified as having haze below $10 \%$ and low peel strength. Further tailoring of film thickness to $20 \mu \mathrm{m}$ can result in haze as low as $\sim 4 \%$, and a low peel strength of $8-10 \mathrm{~N} / 15 \mathrm{~mm}$ at the interfacial sealing temperature of $76-105^{\circ} \mathrm{C}$. These were identified as optimum composition/preparation conditions that allow to design a peelable PLA lidding film to be sealed on PLA container [170]. The peel mechanism of PLA/PBAT films was shown to be a cohesive failure [171].

Biaxial two-layer or multilayer PLA peelable films, with the seal layer made of PLA blended with PBAT in weight PLA/PBAT ratios ranging from 30/70 to 80/20 were patented [171]. Peelable PLA-based films were also prepared by including in formulations PBAT, PBSA and poly( $\varepsilon$-caprolactone) in various compositions [172].

PLA/PBAT blends were also investigated as material for active food packaging, i.e., food packaging that incorporates active ingredients able to extend the shelf life of packaged food $[173,174]$. Special attention was given to inclusion of natural antifungal ingredients able to extend the storage time of bakery products [175]. Srisa and Harnkarnsujarit incorporated trans-cinnamaldehyde, the major component in cinnamon essential oil, into PLA/PBAT 60/40 and 40/40 blends, and demonstrated that addition of this essential oil to blend films extended shelf-life of breads for 21 days, by reducing bacterial and fungal growth. Films containing 2-10 wt\% of trans-cinnamaldehyde showed high antifungal efficacy against Penicillium sp. and Aspergillus niger, the major spoilage fungi of bread, and lower but still effective activity against Rhizopus sp. [176].

Addition of thymol to PLA/PBSA films was also shown to be a successful strategy to develop active packaging film for bakery products [177]. Thymol (2-isopropyl-5- 
methylphenol), is the main monoterpene phenol found in oregano and thyme essential oils [178], with strong antifungal activity against a wide range of microorganisms [179]. The antifungal efficiency PLA/PBSA films containing 3-6 wt $\%$ of thymol was tested for bread packaging, and showed higher efficiency to inhibit growth of Penicillium sp. and Aspergillus niger compared to biaxially oriented polypropylene and plain PLA films containing the same amount of thymol, both in vitro and in packed bread. The antifungal packaging containing $6 \mathrm{wt} \%$ of thymol added to a PLA/PBSA 70/30 could extend the shelf life of bread to 9 days, compared to 3 days of commercial biaxially oriented polypropylene.

PLA/PBSA films containing carvacrol and thymol were tested for packaging of fishery products, specifically for salmon slices [180]. The progressive release of carvacrol and thymol into salmon slices during cold storage could inhibit enzymes activity and hinder decomposition of proteins and volatile basic components, like trimethylamine and biogenic amines. Both essential oils were also effective in hampering oxidation of unsaturated fatty acids in the salmon slices, thus maintaining their nutritional values and extending their preservation by 3-4 days during cold storage [180].

Besides food packaging, PLA is widely used also in additive manufacturing, also known as 3D printing $[4,6,8]$. Additive manufacturing is a layer-by-layer deposition process of an extruded filament designed via a computer-based 3D model. The improvement of mechanical properties of PLA attained by blending with PBAT or PBSA, as well by addition of nanofillers, pushed development of these materials as filaments for 3D printing. PLA/PBAT and PLA/PBSA blends were investigated by a number of researchers, to test their suitability as 3D printing material, either as binary blends, or as compatibilized formulations [181-184], as well as containing micro- and nanofillers [185-187].

A PLA/PBSA composite filament made of $80 \mathrm{wt} \%$ of PLA, $10 \mathrm{wt} \%$ of PBSA and $10 \mathrm{wt} \%$ of modified bone powder was found to have low cytotoxicity, high biocompatibility and printability, making it feasible for 3D printing personalized bone repair applications. Such material has potential to develop customized bones and bone scaffolds by 3D printing [188].

PBSA and PBAT were also used to improve the poor foamability of PLA [72]. Binary PLA/PBAT and PLA/PBSA with weight ratio $75 / 25$ were prepared, and their suitability to develop cellular structures was compared to plain PLA. By tailoring processing conditions, different microcellular structures could be attained, including both open- and closed cell morphologies, with corresponding changes in foaming density. PBSA droplets dispersed within PLA were found to more effectively enhance the cell nucleation and stabilize cell growth, compared to PBAT [72].

\section{Conclusions and Future Perspectives}

The production and utilization of environmentally friendly materials offer stimulating green opportunities. The low cost of PLA with respect to other biobased polymers makes this polyester a very interesting material for many different applications. Furthermore, blends of biobased polymers, suitably mixed to obtain tunable properties, are efficient alternatives to petrol-derived polymers. This literature review aims to demonstrate how PLA/PBAT and PLA/PBSA blends can represent a useful method to obtain biobased materials with improved properties with respect to pure PLA.

Although PLA is immiscible with PBAT and PBSA, improved mechanical properties of the blends with respect to pure PLA can be obtained, thus overcoming the low ductility and high brittleness of PLA. The addition of PBAT and PBSA to PLA promotes biodegradation of PLA in industrial compost, while the PLA presence lowers the biodegradation rate of PBAT and PBSA in home compost or soil. This review reports results on the mechanical, thermal and morphological properties of PLA/PBAT and PLA/PBSA blends, prepared by simple blending or in the presence of coupling agents. The effect of different compatibilizers on the PLA/PBAT and PLA/PBSA blends properties is presented here. Moreover, the review illustrates how the incorporation of solid nanoparticles to the PLA/PBAT and PLA/PBSA blends can be useful to stabilize the morphology and so influence the physical properties and biodegradability of these materials. Depending on the nanoparticles local- 
ization, different properties of the PLA based materials can be obtained, as a function of the interfacial interactions. Thus, nanofiller incorporation is a very favorable technique for the compatibilization of PLA-based blends, with influence also on the biodegradation rate.

Although research on PLA-based blends has been very active in recent years, further studies should be conducted to improve performance and evaluate the best compositions to obtain fully biodegradable materials. An important aspect that deserves to be further investigated in more detail concerns the development of new compatibilizers, environmentally friendly and characterized by a high reactivity, to obtain high-performance blends that can be also fully biobased and biodegradable. Moreover, new types of nanoparticles would deserve to be tested to improve both the compatibility between polymeric phases and the mechanical properties. In addition, nanoparticles can affect the crystallinity of PLA and also the heat resistance properties. These features have been poorly investigated for these materials, and need to be examined in depth. Finally, as reported above, only a few studies have been conducted so far to evaluate the biodegradability of these PLA-based blends, and further investigations would be necessary to investigate, for example, the potential release of microplastics and the polluting effect of possible nanofillers and additives, as well as the effect of the phase composition and the crystallization degree on the biodegradation process. In addition, the full life cycle of these materials should be investigated for a more complete assessment of the environmental sustainability in combination with possible commercial development.

Author Contributions: Conceptualization, E.P. and M.C.R.; writing—original draft preparation, S.C. and E.P.; writing-review and editing, S.C., M.L.D.L., P.C., M.C.R. and E.P. All authors have read and agreed to the published version of the manuscript.

Funding: This research received no external funding.

Informed Consent Statement: Not applicable.

Data Availability Statement: Not applicable.

Conflicts of Interest: The authors declare no conflict of interest.

\section{References}

1. Zhang, Q.; Song, M.; Xu, Y.; Wang, W.; Wang, Z.; Zhang, L. Bio-based polyesters: Recent progress and future prospects. Prog. Polym. Sci. 2021, 120, 101430. [CrossRef]

2. Tian, H.; Tang, Z.; Zhuang, X.; Chen, X.; Jing, X. Biodegradable synthetic polymers: Preparation, functionalization and biomedical application. Prog. Polym. Sci. 2012, 37, 237-280. [CrossRef]

3. Di Lorenzo, M.L.; Androsch, R. (Eds.) Synthesis, Structure and Properties of Poly(lactic acid), Adv Polymerms Science; Springer: Cham, Switzerland, 2018; p. 279.

4. Di Lorenzo, M.L.; Androsch, R. (Eds.) Industrial Applications of Poly(lactic acid), Adv Polymerms Science; Springer: Cham, Switzerland, 2018; p. 282.

5. Dorgan, J.R.; Lehermeier, H.; Mang, M. Thermal and Rheological Properties of Commercial-Grade Poly(Lactic Acid)s. J. Polym. Environ. 2000, 8, 1-9. [CrossRef]

6. Farah, S.; Anderson, D.G.; Langer, R. Physical and mechanical properties of PLA and their functions in widespread applications-A comprehensive review. Adv. Drug Deliv. Rev. 2016, 107, 367-392. [CrossRef]

7. Hamad, K.; Kaseem, M.; Ayyoob, M.; Joo, J.; Deri, F. Polylactic acid blends: The future of green, light and tough. Prog. Polym. Sci. 2018, 85, 83-127. [CrossRef]

8. Nofar, M.; Sacligil, D.; Carreau, P.J.; Kamal, M.R.; Heuzey, M.-C. Poly (lactic acid) blends: Processing, properties and applications. Int. J. Biol. Macromol. 2019, 125, 307-360. [CrossRef] [PubMed]

9. Di Lorenzo, M.L. Poly(L-lactic acid)/Poly(butylene succinate) Biobased Biodegradable Blends. Polym. Rev. 2020, 1-37. [CrossRef]

10. Saeidlou, S.; Huneault, M.A.; Li, H.; Park, C.B. Poly(lactic acid) crystallization. Prog. Polym. Sci. 2012, 37, 1657-1677. [CrossRef]

11. Gan, Z.; Kuwabara, K.; Yamamoto, M.; Abe, H.; Doi, Y. Solid-state structures and thermal properties of aliphatic-aromatic poly(butylene adipate-co-butylene terephthalate) copolyesters. Polym. Degrad. Stab. 2004, 83, 289-300. [CrossRef]

12. Herrera, R.; Franco, L.; Rodríguez-Galán, A.; Puiggalí, J. Characterization and degradation behavior of poly(butylene adipate-coterephthalate)s. J. Polym. Sci. Part A Polym. Chem. 2002, 40, 4141-4157. [CrossRef]

13. Pérez-Camargo, R.A.; Fernández-d'Arlas, B.; Cavallo, D.; Debuissy, T.; Pollet, E.; Avérous, L.; Müller, A.J. Tailoring the structure, morphology, and crystallization of isodimorphic poly(butylene succinate-ran-butylene adipate) random co-polymers by changing composition and thermal history. Macromolecules 2017, 50, 597-608. [CrossRef] 
14. Tserki, V.; Matzinos, P.; Pavlidou, E.; Vachliotis, D.; Panayiotou, C. Biodegradable aliphatic polyesters. Part, I. Properties and biodegradation of poly(butylene succinate-co-butylene adipate). Polym. Degrad. Stab. 2006, 91, 367-376. [CrossRef]

15. Zeng, J.-B.; Li, K.-A.; Du, A.-K. Compatibilization strategies in poly(lactic acid)-based blends. RSC Adv. 2015, 5, 32546-32565. [CrossRef]

16. Nagarajan, V.; Mohanty, A.K.; Misra, M. Perspective on Polylactic Acid (PLA) based Sustainable Materials for Durable Applications: Focus on Toughness and Heat Resistance. ACS Sustain. Chem. Eng. 2016, 4, 2899-2916. [CrossRef]

17. Saini, P.; Arora, M.; Kumar, M.R. Poly(lactic acid) blends in biomedical applications. Adv. Drug Deliv. Rev. 2016, 107, 47-59. [CrossRef] [PubMed]

18. Krishnan, S.; Pandey, P.; Mohanty, S.; Nayak, S.K. Toughening of Polylactic Acid: An Overview of Research Progress. Polym. Technol. Eng. 2015, 55, 1623-1652. [CrossRef]

19. Wang, M.; Wu, Y.; Li, Y.-D.; Zeng, J.-B. Progress in Toughening Poly(lactic acid) with Renewable Polymers. Polym. Rev. 2017, 57, 557-593. [CrossRef]

20. Sangeetha, V.; Deka, H.; Varghese, T.; Nayak, S.K. State of the art and future prospectives of poly(lactic acid) based blends and composites. Polym. Compos. 2018, 39, 81-101. [CrossRef]

21. Koh, J.J.; Zhang, X.; He, C. Fully biodegradable Poly(lactic acid)/Starch blends: A review of toughening strategies. Int. J. Biol. Macromol. 2018, 109, 99-113. [CrossRef]

22. Rosli, N.A.; Ahmad, I.; Anuar, F.H.; Abdullah, I. The contribution of eco-friendly bio-based blends on enhancing the thermal stability and biodegradability of Poly(lactic acid). J. Clean. Prod. 2018, 198, 987-995. [CrossRef]

23. Jin, F.-L.; Hu, R.-R.; Park, S.-J. Improvement of thermal behaviors of biodegradable poly(lactic acid) polymer: A review. Compos. Part B Eng. 2019, 164, 287-296. [CrossRef]

24. Zaaba, N.F.; Ismail, H. A review on tensile and morphological properties of poly (lactic acid) (PLA)/ thermoplastic starch (TPS) blends. Polym. Technol. Mater. 2019, 58, 1945-1964. [CrossRef]

25. Nofar, M.; Salehiyan, R.; Ray, S.S. Rheology of poly(lactic acid)-based systems. Polym. Rev. 2019, 59, 465-509. [CrossRef]

26. Casalini, T.; Rossi, F.; Castrovinci, A.; Perale, G. A Perspective on Polylactic Acid-Based Polymers Use for Nanoparticles Synthesis and Applications. Front. Bioeng. Biotechnol. 2019, 7, 259. [CrossRef] [PubMed]

27. Alias, N.F.; Ismail, H. An overview of toughening polylactic acid by an elastomer. Polym. Technol. Mater. 2019, 58, 1399-1422. [CrossRef]

28. Su, S.; Kopitzky, R.; Tolga, S.; Kabasci, S. Polylactide (PLA) and Its Blends with Poly(butylene succinate) (PBS): A Brief Review. Polymers 2019, 11, 1193. [CrossRef] [PubMed]

29. Zhao, X.; Hu, H.; Wang, X.; Yu, X.; Zhou, W.; Peng, S. Super tough poly(lactic acid) blends: A comprehensive review. RSC Adv. 2020, 10, 13316-13368. [CrossRef]

30. Mehta, R.; Kumar, V.; Bhunia, H.; Upadhyay, S.N. Synthesis of Poly(lactic acid): A Review. J. Macromol. Sci. Part C 2005, 45, 325-349. [CrossRef]

31. Tan, J.; Abdel-Rahman, M.A.; Sonomoto, K. Biorefinery-Based Lactic Acid Fermentation: Microbial Production of Pure Monomer Product. In Synthesis, Structure and Properties of Poly(lactic acid); Di Lorenzo, M.L., Androsch, R., Eds.; Springer: Cham, Switzerland, 2017; pp. 27-66.

32. Byers, J.A.; Biernesser, A.B.; Chiaie, K.D.; Kaur, A.; Kehl, J.A. Catalytic Systems for the Production of Poly(lactic acid). In Synthesis, Structure and Properties of Poly(lactic acid); Di Lorenzo, M.L., Androsch, R., Eds.; Springer: Cham, Switzerland, 2017 ; pp. 67-118.

33. Wang, Y.; Tashiro, Y.; Sonomoto, K. Fermentative production of lactic acid from renewable materials: Recent achievements, prospects, and limits. J. Biosci. Bioeng. 2015, 119, 10-18. [CrossRef] [PubMed]

34. Pan, P.; Inoue, Y. Polymorphism and isomorphism in biodegradable polyesters. Prog. Polym. Sci. 2009, 34, 605-640. [CrossRef]

35. Di Lorenzo, M.L.; Cocca, M.; Malinconico, M. Crystal polymorphism of poly(L-lactic acid) and its influence on thermal properties. Thermochim. Acta 2011, 522, 110-117. [CrossRef]

36. Cocca, M.; Di Lorenzo, M.L.; Malinconico, M.; Frezza, V. Influence of crystal polymorphism on mechanical and barrier properties of poly(L-lactic acid). Eur. Polym. J. 2011, 47, 1073-1080. [CrossRef]

37. Androsch, R.; Di Lorenzo, M.L.; Schick, C. Crystal nucleation in random L/D-lactide copolymers. Eur. Polym. J. 2016, 75, 474-485. [CrossRef]

38. Laycock, B.; Nikolić, M.; Colwell, J.M.; Gauthier, E.; Halley, P.; Bottle, S.; George, G. Lifetime prediction of biodegradable polymers. Prog. Polym. Sci. 2017, 71, 144-189. [CrossRef]

39. Kühnert, I.; Spörer, Y.; Brünig, H.; Tran, N.H.A.; Rudolph, N. Processing of Poly(lactic Acid). In Industrial Applications of Poly(lactic acid); Di Lorenzo, M.L., Androsch, R., Eds.; Springer: Cham, Switzerland, 2017; pp. 1-33.

40. Domenek, S.; Fernandes-Nassar, S.; Ducruet, V. Rheology, Mechanical Properties, and Barrier Properties of Poly(lactic acid). In Synthesis, Structure and Properties of Poly(lactic acid); Di Lorenzo, M.L., Androsch, R., Eds.; Springer: Cham, Switzerland, 2017; pp. 303-341.

41. Jacquel, N.; Saint-Loup, R.; Pascault, J.-P.; Rousseau, A.; Fenouillot, F. Bio-based alternatives in the synthesis of aliphatic-aromatic polyesters dedicated to biodegradable film applications. Polymer 2015, 59, 234-242. [CrossRef]

42. Jian, J.; Xiangbin, Z.; Xianbo, H. An overview on synthesis, properties and applications of poly(butylene-adipate-co-terephthalate)PBAT. Adv. Ind. Eng. Polym. Res. 2020, 3, 19-26. [CrossRef] 
43. Luo, S.; Li, F.; Yu, J.; Cao, A. Synthesis of poly(butylene succinate-co-butylene terephthalate) (PBST) copolyesters with high molecular weights via direct esterification and polycondensation. J. Appl. Polym. Sci. 2010, 115, 2203-2211. [CrossRef]

44. Lee, P.C.; Lee, W.G.; Lee, S.Y.; Chang, H.N. Succinic Acid Production with Reduced by-Product Formation in the Fermentation of Anaerobiospirillum succiniciproducens Using Glycerol as a Carbon Source. Biotechnol. Bioeng. 2001, 72, 41-48. [CrossRef]

45. Cheng, K.-K.; Zhao, X.; Zeng, J.; Zhang, J.-A. Biotechnological production of succinic acid: Current state and perspectives. Biofuels Bioprod. Biorefin. 2012, 6, 302-318. [CrossRef]

46. Bretz, K.; Kabasci, S. Feed-Control Development for Succinic Acid Production with Anaerobiospirillum succinicipro-ducens. Biotechnol. Bioeng. 2012, 109, 1187-1192. [CrossRef]

47. Borges, E.R.; Pereira, N. Succinic acid production from sugarcane bagasse hemicellulose hydrolysate by Actinobacillus succinogenes. J. Ind. Microbiol. Biotechnol. 2011, 38, 1001-1011. [CrossRef]

48. Peters, M.W.; Taylor, J.D.; Jenni, M.; Manzer, L.E.; Henton, D.E. Integrated Process to Selectively Convert Renewable Isobutanol to p-Xylene. U.S. Patent 2011/0087000, 14 April 2011.

49. Berti, C.; Binassi, E.; Colonna, M.; Fiorini, M.; Kannan, G.; Karanam, S.; Mazzacurati, M.; Odeh, I.; Vannini, M. Bio-based Terephthalate Polyesters. WO Patent 2010/078328, 8 July 2009.

50. Polen, T.; Spelberg, M.; Bott, M. Toward biotechnological production of adipic acid and precursors from biorenewables. J. Biotechnol. 2013, 167, 75-84. [CrossRef]

51. Vardon, D.; Franden, M.A.; Johnson, C.; Karp, E.M.; Guarnieri, M.T.; Linger, J.G.; Salm, M.J.; Strathmann, T.J.; Beckham, G.T. Adipic acid production from lignin. Energy Environ. Sci. 2015, 8, 617-628. [CrossRef]

52. Picataggio, S.; Rohrer, T.; DeAnda, K.; Lanning, D.; Reynolds, R.; Mielenz, J.; Eirich, L.D. Metabolic Engineering of Candida Tropicalis for the Production of Long-Chain Dicarboxylic Acids. Nat. Biotechnol. 1992, 10, 894-898. [CrossRef] [PubMed]

53. Rios, J.; Lebeau, J.; Yang, T.; Li, S.; Lynch, M.D. A critical review on the progress and challenges to a more sustainable, cost competitive synthesis of adipic acid. Green Chem. 2021, 23, 3172-3190. [CrossRef]

54. Mondal, D.; Bhowmick, B.; Mollick, M.R.; Maity, D.; Saha, N.R.; Rangarajan, V.; Rana, D.; Sen, R.; Chattopadhyay, D. Antimicrobial activity and biodegradation behavior of poly(butylene adipate-co-terephthalate)/clay nanocomposites. J. Appl. Polym. Sci. 2013, 131, 40079-40088. [CrossRef]

55. Shi, X.; Ito, H.; Kikutani, T. Characterization on mixed-crystal structure and properties of poly(butylene adipate-co-terephthalate) biodegradable fibers. Polymer 2005, 46, 11442-11450. [CrossRef]

56. Cranston, E.; Kawada, J.; Raymond, S.; Morin, F.G.; Marchessault, R.H. Cocrystallization model for synthetic biode-gradable poly(butylene adipate-cobutylene terephthalate). Biomacromolecules 2003, 4, 995-999. [CrossRef]

57. Al-Itry, R.; Lamnawar, K.; Maazouz, A.; Billon, N.; Combeaud, C. Effect of the simultaneous biaxial stretching on the structural and mechanical properties of PLA, PBAT and their blends at rubbery state. Eur. Polym. J. 2015, 68, 288-301. [CrossRef]

58. Chen, X.; Chen, W.; Zhu, G.; Huang, F.; Zhang, J. Synthesis,1H-NMR characterization, and biodegradation behavior of aliphaticaromatic random copolyester. J. Appl. Polym. Sci. 2007, 104, 2643-2649. [CrossRef]

59. Vroman, I.; Tighzert, L. Biodegradable Polymers. Materials 2009, 2, 307-344. [CrossRef]

60. Witt, U.; Müller, R.-J.; Deckwer, W.-D. New biodegradable polyester-copolymers from commodity chemicals with favorable use properties. J. Environ. Polym. Degrad. 1995, 3, 215-223. [CrossRef]

61. Müller, R.-J.; Kleeberg, I.; Deckwer, W.-D. Biodegradation of polyesters containing aromatic constituents. J. Biotechnol. 2001, 86, 87-95. [CrossRef]

62. Zumstein, M.T.; Schintlmeister, A.; Nelson, T.F.; Baumgartner, R.; Woebken, D.; Wagner, M.; Kohler, H.-P.E.; McNeill, K.; Sander, M. Biodegradation of synthetic polymers in soils: Tracking carbon into $\mathrm{CO}_{2}$ and microbial biomass. Sci. Adv. 2018, 4, eaas9024. [CrossRef]

63. Wang, Y.; Bhattacharya, M.; Mano, J.F. Thermal analysis of the multiple melting behavior of poly(butylene succinate-co-adipate). J. Polym. Sci. B Polym. Phys. 2005, 43, 3077-3082. [CrossRef]

64. Ray, S.S.; Bandyopadhyay, J.; Bousmina, M. Effect of Organoclay on the Morphology and Properties of Poly(propylene)/ Poly[(butylene succinate)-co-adipate] Blends. Macromol. Mater. Eng. 2007, 292, 729-747. [CrossRef]

65. Fujimaki, T. Processability and properties of aliphatic polyesters, 'BIONOLLE', synthesized by polycondensation reaction. Polym. Degrad. Stab. 1998, 59, 209-214. [CrossRef]

66. Yang, J.; Pan, P.; Hua, L.; Xie, Y.; Dong, T.; Zhu, B.; Inoue, Y.; Feng, X. Fractionated crystallization, polymorphic crystalline structure, and spherulite morphology of poly(butylene adipate) in its miscible blend with poly(butylene succinate). Polymer 2011, 52, 3460-3468. [CrossRef]

67. Zheng, Y.; Pan, P. Crystallization of biodegradable and biobased polyesters: Polymorphism, cocrystallization, and structureproperty relationship. Prog. Polym. Sci. 2020, 109, 101291. [CrossRef]

68. Debuissy, T.; Pollet, E.; Avérous, L. Synthesis and characterization of bio-based poly (butylene furandicarboxylate)-b-poly (tetramethylene glycol) copolymers. Eur. Polym. J. 2017, 87, 84-98. [CrossRef]

69. Nikolic, M.; Djonlagic, J. Synthesis and characterization of biodegradable poly(butylene succinate-co-butylene adipate)s. Polym. Degrad. Stab. 2001, 74, 263-270. [CrossRef]

70. Su, S.; Duhme, M.; Kopitzky, R. Uncompatibilized PBAT/PLA Blends: Manufacturability, Miscibility and Properties. Materials 2020, 13, 4897. [CrossRef] 
71. Nofar, M.; Oguz, H.; Ovalı, D. Effects of the matrix crystallinity, dispersed phase, and processing type on the morphological, thermal, and mechanical properties of polylactide based binary blends with poly[(butylene adipate)-co-terephthalate] and poly[(butylene succinate)-co-adipate]. J. Appl. Polym. Sci. 2019, 136, 47636. [CrossRef]

72. Nofar, M.; Tabatabaei, A.; Sojoudiasli, H.; Park, C.B.; Carreau, P.; Heuzey, M.-C.; Kamal, M. Mechanical and bead foaming behavior of PLA-PBAT and PLA-PBSA blends with different morphologies. Eur. Polym. J. 2017, 90, 231-244. [CrossRef]

73. Deng, Y.; Yu, C.; Wongwiwattana, P.; Thomas, N.L. Optimising ductility of poly(lactic acid)/poly(butylene adipate-coterephthalate) blends through co-continuous phase morphology. J. Polym. Environ. 2018, 26, 3802-3816. [CrossRef]

74. Gigante, V.; Canesi, I.; Cinelli, P.; Coltelli, M.B.; Lazzeri, A. Rubber Toughening of Polylactic Acid (PLA) with Poly(butylene adipate-co-terephthalate) (PBAT): Mechanical Properties, Fracture Mechanics and Analysis of Ductile-to-Brittle Behavior while Varying Temperature and Test Speed. Eur. Polym. J. 2019, 115, 125-137. [CrossRef]

75. Lu, X.; Zhao, J.; Yang, X.; Xiao, P. Morphology and properties of biodegradable poly (lactic acid)/poly (butylene adipate-coterephthalate) blends with different viscosity ratio. Polym. Test. 2017, 60, 58-67. [CrossRef]

76. Oguz, H.; Dogan, C.; Kara, D.; Ozen, Z.T.; Ovali, D.; Nofar, M. Development of PLA-PBAT and PLA-PBSA bio-blends: Effects of processing type and PLA crystallinity on morphology and mechanical properties. AIP Conf. Proc. 2017, 2055, 030003. [CrossRef]

77. Nofar, M.; Maani, A.; Sojoudi, H.; Heuzey, M.C.; Carreau, P.J. Interfacial and rheological properties of PLA/PBAT and PLA/PBSA blends and their morphological stability under shear flow. J. Rheol. 2015, 59, 317-333. [CrossRef]

78. Gua, S.-Y.; Zhang, K.; Ren, J.; Zhan, H. Melt rheology of polylactide/poly(butylene adipate-co-terephthalate) blends. Carbohyrate Polym. 2008, 74, 79-85. [CrossRef]

79. Dil, E.J.; Carreau, P.J.; Favis, B.D. Morphology, miscibility and continuity development in poly(lactic acid)/poly(butylene adipate-co-terephthalate) blends. Polymer 2015, 68, 202-212. [CrossRef]

80. Pivsa-Art, W.; Pivsa-Art, S.; Fujii, K.; Nomura, K.; Ishimoto, K.; Aso, Y.; Yamane, H.; Ohara, H. Compression molding and melt-spinning of the blends of poly(lactic acid) and poly(butylene succinate-co-adipate). J. Appl. Polym. Sci. 2014, $132,41856$. [CrossRef]

81. Ojijo, V.; Ray, S.S.; Sadiku, R. Concurrent Enhancement of Multiple Properties in Reactively Processed Nanocomposites of Polylactide/Poly[(butylene succinate)-co-adipate] Blend and Organoclay. Macromol. Mater. Eng. 2014, 299, 596-608. [CrossRef]

82. Chiu, H.-T.; Huang, S.-Y.; Chen, Y.-F.; Kuo, M.-T.; Chiang, T.-Y.; Chang, C.-Y.; Wang, Y.-H. Heat Treatment Effects on the Mechanical Properties and Morphologies of Poly (Lactic Acid)/Poly (Butylene Adipate-co-terephthalate) Blends. Int. J. Polym. Sci. 2013, 2013, 1-11. [CrossRef]

83. Quero, E.; Müller, A.J.; Signori, F.; Coltelli, M.-B.; Bronco, S. Isothermal Cold-Crystallization of PLA/PBAT Blends With and Without the Addition of Acetyl Tributyl Citrate. Macromol. Chem. Phys. 2012, 213, 36-48. [CrossRef]

84. Ojijo, V.; Sinha Ray, S.; Sadiku, R. Role of Specific Interfacial Area in Controlling Properties of Immiscible Blends of Bio-degradable Polylactide and Poly[(butylene succinate)-co-adipate]. ACS Appl. Mater. Interfaces 2012, 4, 6690-6701. [CrossRef]

85. Pivsa-Art, W.; Pavasupree, S.; O-Charoen, N.; Insuan, U.; Jailak, P.; Pivsa-Art, S. Preparation of Polymer Blends between Poly (L-lactic acid), Poly (butylene succinate-co-adipate) and Poly (butylene adipate-co-terephthalate) for Blow Film Industrial Application. Energy Procedia 2011, 9, 581-588. [CrossRef]

86. Li, K.; Peng, J.; Turng, L.-S.; Huang, H.-X. Dynamic rheological behavior and morphology of polylactide/poly(butylenes adipate-co-terephthalate) blends with various composition ratios. Adv. Polym. Technol. 2011, 30, 150-157. [CrossRef]

87. Farsetti, S.; Cioni, B.; Lazzeri, A. Physico-Mechanical Properties of Biodegradable Rubber Toughened Polymers. Macromol. Symp. 2011, 301, 82-89. [CrossRef]

88. Zhao, P.; Liu, W.; Wu, Q.; Ren, J. Preparation, Mechanical, and Thermal Properties of Biodegradable Polyesters/Poly(lactic acid) Blends. J. Nanomater. 2010, 2010, 1-8. [CrossRef]

89. Yeh, J.-T.; Tsou, C.-H.; Huang, C.-Y.; Chen, K.-N.; Wu, C.-S.; Chai, W.-L. Compatible and crystallization properties of poly(lactic acid)/poly(butylene adipate-co-terephthalate) blends. J. Appl. Polym. Sci. 2009, 116, 680-687. [CrossRef]

90. Xiao, H.; Lu, W.; Yeh, J.-T. Crystallization Behavior of Fully Biodegradable Poly(Lacric acid)/Poly(Butylene Adipate-coTerephthalate) Blends. J. Appl. Polym. Sci. 2009, 112, 3754-3763. [CrossRef]

91. Ding, Y.; Feng, W.; Lu, B.; Wang, P.; Wang, G.; Ji, J. PLA-PEG-PLA tri-block copolymers: Effective compatibilizers for promotion of the interfacial structure and mechanical properties of PLA/PBAT blends. Polymer 2018, 146, 179-187. [CrossRef]

92. Ding, Y.; Feng, W.; Huang, D.; Lu, B.; Wang, P.; Wang, G.; Ji, J. Compatibilization of immiscible PLA-based biodegradable polymer blends using amphiphilic di-block copolymers. Eur. Polym. J. 2019, 118, 45-52. [CrossRef]

93. Coltelli, M.-B.; Bronco, S.; Chinea, C. The effect of free radical reactions on structure and properties of poly(lactic acid) (PLA) based blends. Polym. Degrad. Stab. 2010, 95, 332-341. [CrossRef]

94. Ma, P.; Cai, X.; Zhang, Y.; Wang, S.; Dong, W.; Chen, M.; Lemstra, P. In-situ compatibilization of poly(lactic acid) and poly(butylene adipate-co-terephthalate) blends by using dicumyl peroxide as a free-radical initiator. Polym. Degrad. Stab. 2014, 102, 145-151. [CrossRef]

95. Signori, F.; Boggioni, A.; Righetti, M.C.; Rondán, C.E.; Bronco, S.; Ciardelli, F. Evidences of Transesterification, Chain Branching and Cross-Linking in a Biopolyester Commercial Blend upon Reaction with Dicumyl Peroxide in the Melt. Macromol. Mater. Eng. 2014, 300, 153-160. [CrossRef] 
96. Ai, X.; Li, X.; Yu, Y.; Pan, H.; Yang, J.; Wang, N.; Yang, H.; Zhang, H.; Dong, L. The Mechanical, Thermal, Rheological and Morphological Properties of PLA/PBAT Blown Films by Using Bis(tert-butyl dioxy isopropyl) Benzene as Crosslinking Agent. Polym. Eng. Sci. 2019, 59, E227-E236. [CrossRef]

97. Coltelli, M.-B.; Toncelli, C.; Ciardelli, F.; Bronco, S. Compatible blends of biorelated polyesters through catalytic trans-esterification in the melt. Polym. Degrad. Stab. 2011, 96, 982-990. [CrossRef]

98. Lin, S.; Guo, W.; Chen, C.; Ma, J.; Wang, B. Mechanical properties and morphology of biodegradable poly(lactic acid)/poly(butylene adipate-co-terephthalate) blends compatibilized by transesterification. Mater. Design 2012, 36, 604-608. [CrossRef]

99. Ojijo, V.; Sinha Ray, S.; Sadiku, R. Toughening of Biodegradable Polylactide/Poly(butylene succinate-co-adipate) Blends via in Situ Reactive Compatibilization. ACS Appl. Mater. Interfaces 2013, 5, 4266-4276. [CrossRef]

100. Zhang, N.; Wang, Q.; Ren, J.; Wang, L. Preparation and properties of biodegradable poly(lactic acid)/poly(butylene adipate-coterephthalate) blend with glycidyl methacrylate as reactive processing agent. J. Mater. Sci. 2009, 44, 250-256. [CrossRef]

101. $\mathrm{Wu}, \mathrm{N}$; Z Zhang, H. Mechanical properties and phase morphology of super-tough PLA/PBAT/EMA-GMA multicomponent blends. Mater. Lett. 2017, 192, 17-20. [CrossRef]

102. Eslami, H.; Kamal, M.R. Effect of a chain extender on the rheological and mechanical properties of biodegradable poly(lactic acid)/poly[(butylene succinate)-co-adipate] blends. J. Appl. Polym. Sci. 2013, 129, 2418-2428. [CrossRef]

103. Mallegni, N.; Phuong, T.V.; Coltelli, M.-B.; Cinelli, P.; Lazzeri, A. Poly(lactic acid) (PLA) Based Tear Resistant and Bio-degradable Flexible Films by Blown Film Extrusion. Materials 2018, 11, 148. [CrossRef] [PubMed]

104. Zhao, Y.; Zhao, B.; Wei, B.; Wei, Y.; Yao, J.; Zhang, H.; Chen, X.; Shao, Z. Enhanced compatibility between poly(lactic acid) and poly (butylene adipate-co-terephthalate) by incorporation of N-halamine epoxy precursor. Int. J. Biol. Macromol. 2020, 165, 460-471. [CrossRef] [PubMed]

105. Al-Itry, R.; Lamnawar, K.; Maazouz, A. Improvement of thermal stability, rheological and mechanical properties of PLA, PBAT and their blends by reactive extrusion with functionalized epoxy. Polym. Degrad. Stab. 2012, 97, 1898-1914. [CrossRef]

106. Al-Itry, R.; Lamnawar, K.; Maazouz, A. Biopolymer Blends Based on Poly (lactic acid): Shear and Elongation Rheology/Structure/Blowing Process Relationships. Polymers 2015, 7, 939-962. [CrossRef]

107. Arruda, L.C.; Magaton, M.; Bretas, R.E.S.; Ueki, M.M. Influence of chain extender on mechanical, thermal and morphological properties of blown films of PLA/PBAT blends. Polym. Test. 2015, 43, 27-37. [CrossRef]

108. Ojijo, V.; Sinha Ray, S. Super toughened biodegradable polylactide blends with non-linear copolymer interfacial archi-tecture obtained via facile in-situ reactive compatibilization. Polymer 2015, 80, 1-17. [CrossRef]

109. Palai, B.; Mohanty, S.; Nayak, S.K. Synergistic effect of polylactic acid(PLA) and Poly(butylene succinate-co-adipate) (PBSA) based sustainable, reactive, super toughened eco-composite blown films for flexible packaging applications. Polym. Test. 2020, 83, 106130. [CrossRef]

110. Dong, W.; Zou, B.; Yan, Y.; Ma, P.; Chen, M. Effect of Chain-Extenders on the Properties and Hydrolytic Degradation Behavior of the Poly(lactide)/Poly(butylene adipate-co-terephthalate) Blends. Int. J. Mol. Sci. 2013, 14, 20189-20203. [CrossRef] [PubMed]

111. Wang, X.; Peng, S.; Chen, H.; Yu, X.; Zhao, X. Mechanical properties, rheological behaviors, and phase morphologies of high-toughness PLA/PBAT blends by in-situ reactive compatibilization. Compos. Part. B Eng. 2019, 173, 107028. [CrossRef]

112. Li, X.; Yan, X.; Yang, J.; Pan, H.; Gao, G.; Zhang, H.; Dong, L. Improvement of compatibility and mechanical properties of the poly(lactic acid)/poly(butylene adipate-co -terephthalate) blends and films by reactive extrusion with chain extender. Polym. Eng. Sci. 2018, 58, 1868-1878. [CrossRef]

113. Li, X.; Ai, X.; Pan, H.; Yang, J.; Gao, G.; Zhang, H.; Yang, H.; Dong, L. The morphological, mechanical, rheological, and thermal properties of PLA/PBAT blown films with chain extender. Polym. Adv. Technol. 2018, 29, 1706-1717. [CrossRef]

114. Wu, D.D.; Guo, Y.; Huang, A.P.; Xu, R.W.; Liu, P. Effect of the multi-functional epoxides on the thermal, mechanical and rheological properties of poly(butylene adipate-co-terephthalate)/polylactide blends. Polym. Bull. 2020, 1-25. [CrossRef]

115. Farias da Silva, J.M.; Soares, B.G. Epoxidized cardanol-based prepolymer as promising biobased compatibilizing agent for PLA/PBAT blends. Polym. Test. 2021, 93, 106889. [CrossRef]

116. Al-Itry, R.; Lamnawar, K.; Maazouz, A. Reactive extrusion of PLA, PBAT with a multi-functional epoxide: Physico-chemical and rheological properties. Eur. Polym. J. 2014, 58, 90-102. [CrossRef]

117. Carbonell-Verdu, A.; Ferri, J.M.; Dominici, F.; Boronat, T.; Sánchez-Nacher, L.; Balart, R.; Torre, L. Manufacturing and compatibilization of PLA/PBAT binary blends by cottonseed oil-based derivatives. Express Polym. Lett. 2018, 12, 808-823. [CrossRef]

118. Teamsinsungvon, A.; Ruksakulpiwat, Y.; Jarukumjorn, K. Preparation and Characterization of Poly(lactic acid)/Poly(butylene adipate-co-terepthalate) Blends and Their Composite. Polymer-Plastics Technol. Engineering 2013, 52, 1362-1367. [CrossRef]

119. He, H.; Wang, G.; Chen, M.; Xiong, C.; Li, Y.; Tong, Y. Effect of Different Compatibilizers on the Properties of Poly (Lactic Acid)/Poly (Butylene Adipate-co-Terephthalate) Blends Prepared under Intense Shear Flow Field. Materials 2020, $13,2094$. [CrossRef]

120. Nofar, M.; Salehiyan, R.; Ciftci, U.; Jalali, A.; Durmus, A. Ductility improvements of PLA-based binary and ternary blends with controlled morphology using PBAT, PBSA, and nanoclay. Compos. Part. B Eng. 2020, 182, 107661. [CrossRef]

121. Malwela, T.; Sinha Ray, S. Role of Organoclay in Controlling the Morphology and Crystal-Growth Behavior of Biodegradable Polymer-Blend Thin Films Studied Using Atomic Force Microscopy. Macromol. Mater. Eng. 2014, 299, 1106-1115. [CrossRef] 
122. Eslami, H.; Kamal, M.R. Elongational rheology of biodegradable poly (lactic acid)/poly [(butylene succinate)-co-adipate] binary blends and poly (lactic acid)/poly [(butylene succinate)-co-adipate]/clay ternary nanocomposites. J. Appl. Polym. Sci. 2012, 127, 2290-2306. [CrossRef]

123. Ojijo, V.; Ray, S.S.; Sadiku, R. Effect of Nanoclay Loading on the Thermal and Mechanical Properties of Biodegradable Polylactide/Poly[(butylene succinate)-co-adipate] Blend Composites. ACS Appl. Mater. Interfaces 2012, 4, 2395-2405. [CrossRef]

124. Mhlabeni, T.; Pillai, S.K.; Ray, S.S. Effect of organically modified layered double hydroxides on the properties of poly(lactic acid)/poly[(butylene succinate)-co-adipate] immiscible blends. J. Appl. Polym. Sci. 2019, 137, 48654. [CrossRef]

125. Shahlari, M.; Lee, S. Mechanical and morphological properties of poly(butylene adipate-co-terephthalate) and poly(lactic acid) blended with organically modified silicate layers. Polym. Eng. Sci. 2012, 52, 1420-1428. [CrossRef]

126. Lee, S.; Kim, M.; Song, H.Y.; Hyun, K. Characterization of the Effect of Clay on Morphological Evaluations of PLA/Biodegradable Polymer Blends by FT-Rheology. Macromolecules 2019, 52, 7904-7919. [CrossRef]

127. Nofar, M.; Heuzey, M.-C.; Carreau, P.J.; Kamal, M.R. Effects of nanoclay and its localization on the morphology stabilization of PLA/PBAT blends under shear flow. Polymer 2016, 98, 353-364. [CrossRef]

128. Guo, Y.; He, S.; Yang, K.; Xue, Y.; Zuo, X.; Yu, Y.; Liu, Y.; Chang, C.-C.; Rafailovich, M.H. Enhancing the Mechanical Properties of Biodegradable Polymer Blends Using Tubular Nanoparticle Stitching of the Interfaces. ACS Appl. Mater. Interfaces 2016, 8, 17565-17573. [CrossRef]

129. Moustafa, H.; El Kissi, N.; Abou-Kandil, A.I.; Abdel-Aziz, M.S.; Dufresne, A. PLA/PBAT Bionanocomposites with Antimicrobial Natural Rosin for Green Packaging. ACS Appl. Mater. Interfaces 2017, 9, 20132-20141. [CrossRef] [PubMed]

130. Jiang, L.; Liu, B.; Zhang, J. Properties of Poly(lactic acid)/Poly(butylene adipate-co-terephthalate)/Nanoparticle Ternary Composites. Ind. Eng. Chem. Res. 2009, 48, 7594-7602. [CrossRef]

131. Kumar, M.; Mohanty, S.; Nayak, S.K.; Rahail Parvaiz, M. Effect of glycidyl methacrylate (GMA) on the thermal, me-chanical and morphological property of biodegradable PLA/PBAT blend and its nanocomposites. Bioresour. Technol. 2010, 101, 8406-8415. [CrossRef] [PubMed]

132. Mohapatra, A.K.; Mohanty, S.; Nayak, S.K. Study of Thermo-Mechanical and Morphological Behaviour of Biodegradable PLA/PBAT/Layered Silicate Blend Nanocomposites. J. Polym. Environ. 2014, 22, 398-408. [CrossRef]

133. Mirzadeh, A.; Ghasemi, H.; Mahrous, F.; Kamal, M.R. Reactive extrusion effects on rheological and mechanical properties of poly(lactic acid)/poly[(butylene succinate)-co-adipate]/epoxy chain extender blends and clay nanocomposites. J. Appl. Polym. Sci. 2015, 132, 42664. [CrossRef]

134. Perrone de, L.; Freitas, A.L.; Tonini Filho, L.R.; Schmid Calvao, P.; Catelli de Souza, A.M. Effect of montmorillonite and chain extender on rheological, morphological and biodegradation behavior of PLA/PBAT blends. Polym. Test. 2017, 62, 189-195. [CrossRef]

135. Ko, S.W.; Hong, M.K.; Park, B.J.; Gupta, R.K.; Choi, H.J.; Bhattacharya, S.N. Morphological and rheological characteri-zation of multi-walled carbon nanotube/PLA/PBAT blend nanocomposites. Polym. Bull. 2009, 63, 125-134. [CrossRef]

136. Urquijo, J.; Aranburu, N.; Dagréou, S.; Guerrica-Echevarría, G.; Eguiazábal, J. CNT-induced morphology and its effect on properties in PLA/PBAT-based nanocomposites. Eur. Polym. J. 2017, 93, 545-555. [CrossRef]

137. Zhou, S.; Hrymak, A.N.; Kamal, M.R. Properties of microinjection-molded multi-walled carbon nanotubes-filled poly(lactic acid)/poly[(butylene succinate)-co-adipate] blend nanocomposites. J. Mater. Sci. 2018, 53, 9013-9025. [CrossRef]

138. Dil, E.J.; Favis, B.D. Localization of micro- and nano-silica particles in heterophase poly(lactic acid)/poly(butylene adipate-coterephthalate) blends. Polymer 2015, 76, 295-306. [CrossRef]

139. Dil, E.J.; Virgilio, N.; Favis, B.D. The effect of the interfacial assembly of nano-silica in poly(lactic acid)/poly(butylene adipate-coterephthalate) blends on morphology, rheology and mechanical properties. Eur. Polym. J. 2016, 85, 635-646. [CrossRef]

140. Nofar, M.; Salehiyan, R.; Ray, S.S. Influence of nanoparticles and their selective localization on the structure and properties of polylactide-based blend nanocomposites. Compos. Part B 2021, 215, 108845. [CrossRef]

141. Prudnikova, S.V.; Vinogradova, O.N.; Trusova, M.Y. Specific character of bacterial biodegradation of polyhydroxyalkanoates with different chemical structure in soil. Dokl. Biochem. Biophys. 2017, 473, 94-97. [CrossRef]

142. Woodard, L.N.; Grunlan, M.A. Hydrolytic Degradation and Erosion of Polyester Biomaterials. ACS Macro Lett. 2018, 7, 976-982. [CrossRef]

143. Sevim, K.; Pan, J. A model for hydrolytic degradation and erosion of biodegradable polymers. Acta Biomater. 2018, 66, 192-199. [CrossRef] [PubMed]

144. Shockley, M.F.; Muliana, A.H. Modeling temporal and spatial changes during hydrolytic degradation and erosion in biodegradable polymers. Polym. Degrad. Stab. 2020, 180, 109298. [CrossRef]

145. Johnson, A.N.; Barlow, D.E.; Kelly, A.L.; Varaljay, V.A.; Crookes-Goodson, W.J.; Biffinger, J.C. Current progress towards understanding the biodegradation of synthetic condensation polymers with active hydrolases. Polym. Int. 2021, 70, 977-983. [CrossRef]

146. Lu, Z.; Reif, R.; Gan, J. Isomer-specific biodegradation of nonylphenol in an activated sludge bioreactor and structurebiodegradability relationship. Water Res. 2015, 68, 282-290. [CrossRef] [PubMed]

147. Genovese, L. New eco-friendly random copolyesters based on poly(propylene cyclohexanedicarboxylate): Structure-properties relationships. Express Polym. Lett. 2015, 9, 972-983. [CrossRef] 
148. Beran, E.; Hull, S.; Steininger, M. The Relationship Between the Chemical Structure of Poly(alkylene glycol)s and Their Aerobic Biodegradability in an Aqueous Environment. J. Polym. Environ. 2013, 21, 172-180. [CrossRef]

149. Corti, A.; Cinelli, P.; D'Antone, S.; Kenawy, E.-R.-; Solaro, R. Biodegradation of poly(vinyl alcohol) in soil environment: Influence of natural organic fillers and structural parameters. Macromol. Chem. Phys. 2002, 203, 1526-1531. [CrossRef]

150. Chiellini, E.; Cinelli, P.; Chiellini, F.; Imam, S.H. Environmentally Degradable Bio-Based Polymeric Blends and Composites. Macromol. Biosci. 2004, 4, 218-231. [CrossRef]

151. Gorrasi, G.; Pantani, R. Effect of PLA grades and morphologies on hydrolytic degradation at composting temperature: Assessment of structural modification and kinetic parameters. Polym. Degrad. Stab. 2013, 98, 1006-1014. [CrossRef]

152. Karamanlioglu, M.; Preziosi, R.; Robson, G.D. Abiotic and biotic environmental degradation of the bioplastic polymer poly(lactic acid): A review. Polym. Degrad. Stab. 2017, 137, 122-130. [CrossRef]

153. Husárová, L.; Pekarova, S.; Stloukal, P.; Kucharzcyk, P.; Verney, V.; Commereuc, S.; Ramone, A.; Koutny, M. Identification of important abiotic \& biotic factors in the biodegradation of PLA. Int. J. Biol. Macromol. 2014, 71, 155-162. [CrossRef]

154. Mueller, R.-J. Biological degradation of synthetic polyesters-Enzymes as potential catalysts for polyester recycling. Process. Biochem. 2006, 41, 2124-2128. [CrossRef]

155. Tokiwa, Y.; Jarerat, A. Biodegradation of poly(l-lactide). Biotechnol. Lett. 2004, 26, 771-777. [CrossRef]

156. Raquez, J.-M.; Habibi, Y.; Murariu, M.; Dubois, P. Polylactide (PLA)-based nanocomposites. Prog. Polym. Sci. 2013, 38, 1504-1542. [CrossRef]

157. Ray, S.S.; Yamada, K.; Okamoto, M.; Ueda, K. New polylactide-layered silicate nanocomposites. 2. Concurrent improvements of material properties, biodegradability and melt rheology. Polymer 2003, 44, 857-866. [CrossRef]

158. Stloukal, P.; Pekařová, S.; Kalendova, A.; Mattausch, H.; Laske, S.; Holzer, C.; Chitu, L.; Bodner, S.C.; Maier, G.; Slouf, M.; et al. Kinetics and mechanism of the biodegradation of PLA/clay nanocomposites during thermophilic phase of composting process. Waste Manag. 2015, 42, 31-40. [CrossRef]

159. Fukushima, K.; Gimenez, E.; Cabedo, L.; Lagaron, J.M.; Feijoo, J.L. Biotic degradation of poly(DL-lactide) based na-naocomposits. Polym. Degrad. Stab. 2012, 97, 1278-1284. [CrossRef]

160. Ferreira, F.V.; Cividanes, L.; Gouveia, R.; Lona, L. An overview on properties and applications of poly(butylene adipate-coterephthalate)-PBAT based composites. Polym. Eng. Sci. 2019, 59, E7-E15. [CrossRef]

161. Weng, Y.-X.; Jin, Y.-J.; Meng, Q.-Y.; Wang, L.; Zhang, M.; Wang, Y.-Z. Biodegradation behavior of poly(butylene adipate-coterephthalate) (PBAT), poly(lactic acid) (PLA), and their blend under soil conditions. Polym. Test. 2013, 32, 918-926. [CrossRef]

162. Palsikowski, P.A.; Kuchnier, C.N.; Pinheiro, I.F.; Morales, A.R. Biodegradation in Soil of PLA/PBAT Blends Compatibilized with Chain Extender. J. Polym. Environ. 2017, 26, 330-341. [CrossRef]

163. Fu, Y.; Wu, G.; Bian, X.; Zeng, J.; Weng, Y. Biodegradation Behavior of Poly(Butylene Adipate-co-Terephthalate) (PBAT), Poly(lactic acid) (PLA), and Their Blend in Freshwater with Sediment. Molecules 2020, 25, 3946. [CrossRef] [PubMed]

164. Girdthep, S.; Worajittiphon, P.; Leejarkpai, T.; Molloy, R.; Punyodom, W. Effect of silver-loaded kaolinite on real ageing, hydrolytic degradation, and biodegradation of composite blown films based on poly(lactic acid) and poly(butylene adipate-co-terephthalate). Eur. Polym. J. 2016, 82, 244-259. [CrossRef]

165. Ratto, J.A.; Stenhouse, P.J.; Auerbach, M.; Mitchell, J.; Farrell, R. Processing, performance and biodegradability of a thermoplastic aliphatic polyester/starch system. Polymer 1999, 40, 6777-6788. [CrossRef]

166. Malwela, T.; Sinha Ray, S. Enzymatic degradation behavior of nanoclay reinforcedbiodegradable PLA/PBSA blend composites. Int. J. Biol. Macromol. 2015, 77, 131-142. [CrossRef]

167. Pivsa-Art, S.; Kord-Sa-Ard, J.; Sijong, W.; Pivsa-Art, W.; Ohara, H.; Yamane, H. Biodegradation in Landfilled of Biode-gradable Micro-braided Yarn. Energy Procedia 2016, 89, 282-290. [CrossRef]

168. Zhang, J.; Manias, E.; Polizos, G.; Huh, J.-Y.; Ophir, A.; Songtipya, P.; Jimenez-Gasco, M.D.M. Tailored Polyethylene Nanocomposite Sealants: Broad-Range Peelable Heat-Seals Through Designed Filler/Polymer Interfaces. J. Adhes. Sci. Technol. 2009, 23, 709-737. [CrossRef]

169. Pettersen, M.K.; Bardet, S.; Nilsen, J.; Fredriksen, S.B. Evaluation and suitability of biomaterials for modified atmosphere packaging of fresh salmon fillets. Packag. Technol. Sci. 2011, 24, 237-248. [CrossRef]

170. Liewchirakorn, P.; Aht-Ong, D.; Chinsirikul, W. Practical Approach in Developing Desirable Peel-Seal and Clear Lidding Films Based on Poly(Lactic Acid) and Poly(Butylene Adipate-co-Terephthalate) Blends. Packag. Technol. Sci. 2017, 31, 296-309. [CrossRef]

171. Busch, D.; Klein, D.; Schmitz, B. Peelable Sealable PLA Film. WO Patent 2007/113077, 11 October 2007.

172. Narita, J.; Sawai, T.; Takeishi, I.; Itoh, S. Aliphatic Polyester Compositions, Film Made Thereof and Laminates Thereof. U.S. Patent No. 6,521,336 B2, 18 February 2003.

173. Auras, R.; Harte, B.; Selke, S. An Overview of Polylactides as Packaging Materials. Macromol. Biosci. 2004, 4, 835-864. [CrossRef] [PubMed]

174. Wen, P.; Zhu, D.-H.; Feng, K.; Liu, F.-J.; Lou, W.-Y.; Li, N.; Zong, M.-H.; Wu, H. Fabrication of electrospun polylactic acid nanofilm incorporating cinnamon essential oil/ $\beta$-cyclodextrin inclusion complex for antimicrobial packaging. Food Chem. 2016, 196, 996-1004. [CrossRef]

175. Qian, M.; Liu, D.; Zhang, X.; Yin, Z.; Ismail, B.B.; Ye, X.; Guo, M. A review of active packaging in bakery products: Applications and future trends. Trends Food Sci. Technol. 2021, 114, 459-471. [CrossRef] 
176. Srisa, A.; Harnkarnsujarit, N. Antifungal films from trans-cinnamaldehyde incorporated poly (lactic acid) and poly (butylene adipate-co-terephthalate) for bread packaging. Food Chem. 2020, 333, 127537. [CrossRef] [PubMed]

177. Suwanamornlert, P.; Kerddonfag, N.; Sane, A.; Chinsirikul, W.; Zhou, W.; Chonhenchob, V. Poly (lactic acid)/poly (butylenesuccinate-co-adipate)(PLA/PBSA) blend films containing thymol as alternative to synthetic preservatives for active packaging of bread. Food Packag. Shelf Life 2020, 25, 100515. [CrossRef]

178. Kulisic, T.; Radonic, A.; Katalinic, V.; Milos, M. Use of different methods for testing antioxidative activity of oregano essential oil. Food Chem. 2004, 85, 633-640. [CrossRef]

179. Ribes, S.; Ruiz-Rico, M.; Pérez-Esteve, É.; Fuentes, A.; Talens, P.; Martínez-Máñez, R.; Barat, J.M. Eugenol and thymol immobilised on mesoporous silica-based material as an innovative antifungal system: Application in strawberry jam. Food Control. 2017, 81, 181-188. [CrossRef]

180. Yang, C.; Tang, H.; Wang, Y.; Liu, Y.; Wang, J.; Shi, W.; Li, L. Development of PLA-PBSA based biodegradable active film and its application to salmon slices. Food Packag. Shelf Life 2019, 22, 100393. [CrossRef]

181. Lyu, Y.; Chen, Y.; Lin, Z.; Zhang, J.; Shi, X. Manipulating phase structure of biodegradable PLA/PBAT system: Effects on dynamic rheological responses and 3D printing. Compos. Sci. Technol. 2020, 200, 108399. [CrossRef]

182. Cardoso, P.H.M.; Coutinho, R.R.T.P.; Drummond, F.R.; Da Conceição, M.D.N.; Thiré, R.M.D.S.M. Evaluation of Printing Parameters on Porosity and Mechanical Properties of 3D Printed PLA/PBAT Blend Parts. Macromol. Symp. 2020, $394,2000157$. [CrossRef]

183. Andrzejewski, J.; Cheng, J.; Anstey, A.; Mohanty, A.K.; Misra, M. Development of toughened blends of poly (lactic acid) and poly (butylene adipate-co-terephthalate) for $3 \mathrm{~d}$ printing applications: Compatibilization methods and material performance evaluation. ACS Sustain. Chem. Eng. 2020, 8, 6576-6589. [CrossRef]

184. Lyu, Y.; Zhao, H.; Wen, X.; Lin, L.; Schlarb, A.K.; Shi, X. Optimization of 3D printing parameters for high-performance biodegradable materials. J. Appl. Polym. Sci. 2021, 138, 50782. [CrossRef]

185. Singamneni, S.; Smith, D.; LeGuen, M.-J.; Truong, D. Extrusion 3D Printing of Polybutyrate-Adipate-Terephthalate-Polymer Composites in the Pellet Form. Polymers 2018, 10, 922. [CrossRef] [PubMed]

186. Prasong, W.; Muanchan, P.; Ishigami, A.; Thumsorn, S.; Kurose, T.; Ito, H. Properties of 3D Printable Poly(lactic acid)/Poly(butylene adipate-co-terephthalate) Blends and Nano Talc Composites. J. Nanomater. 2020, 2020, 1-16. [CrossRef]

187. Prasong, W.; Ishigami, A.; Thumsorn, S.; Kurose, T.; Ito, H. Improvement of Interlayer Adhesion and Heat Resistance of Biodegradable Ternary Blend Composite 3D Printing. Polymers 2021, 13, 740. [CrossRef]

188. Wan, M.; Liu, S.; Huang, D.; Qu, Y.; Hu, Y.; Su, Q.; Zheng, W.; Dong, X.; Zhang, H.; Wei, Y.; et al. Biocompatible heterogeneous bone incorporated with polymeric biocomposites for human bone repair by 3D printing technology. J. Appl. Polym. Sci. 2021, 138, 50114. [CrossRef] 